\title{
Role of Hippocampal $\beta$-Adrenergic and Glucocorticoid Receptors in the Novelty-Induced Enhancement of Fear Extinction
}

\author{
Jian-Feng Liu, ${ }^{1,2 *}$ Chang Yang, ${ }^{1 *}$ Jia-Hui Deng, ${ }^{1,2 *}$ Wei Yan, ${ }^{1,2}$ Hui-Min Wang, ${ }^{1,2}$ Yi-Xiao Luo, ${ }^{1,2}$ Hai-Shui Shi, ${ }^{4}$ \\ Shi-Qiu Meng, ${ }^{1,2}$ Bai-Sheng Chai, ${ }^{3}$ Qin Fang, ${ }^{3}$ Ning Chai, ${ }^{5}$ Yan-Xue Xue, ${ }^{2}$ Jia Sun, ${ }^{3}$ Chen Chen, ${ }^{1,2}$ Xue-Yi Wang, ${ }^{5}$ \\ Ji-Shi Wang, ${ }^{3}$ and Lin $\mathrm{Lu}^{1,2,6}$ \\ ${ }^{1}$ Institute of Mental Health/Peking University Sixth Hospital and Key Laboratory of Mental Health, National Clinical Research Center for Mental Disorders \\ and ${ }^{2}$ National Institute on Drug Dependence, Peking University, Beijing 100191, China, ${ }^{3}$ Affiliated Hospital and School of Pharmacy, Guiyang Medical \\ University, Guiyang 550004, China, ${ }^{4}$ Department of Biochemistry and Molecular Biology, Basic Medical College, Hebei Medical University, Shijiazhuang \\ 050017, China, ${ }^{5}$ Institute of Mental Health and Hebei Brain Ageing and Cognitive Neuroscience Laboratory, Hebei Medical University, Shijiazhuang 050031, \\ China, and ${ }^{\circ}$ Peking-Tsinghua Center for Life Sciences and PKU-IDG/McGovern Institute for Brain Research, Peking University, Beijing 100871, China
}

Fear extinction forms a new memory but does not erase the original fear memory. Exposure to novelty facilitates transfer of short-term extinction memory to long-lasting memory. However, the underlying cellular and molecular mechanisms are still unclear. Using a classical contextual fear-conditioning model, we investigated the effect of novelty on long-lasting extinction memory in rats. We found that exposure to a novel environment but not familiar environment $1 \mathrm{~h}$ before or after extinction enhanced extinction long-term memory (LTM) and reduced fear reinstatement. However, exploring novelty $6 \mathrm{~h}$ before or after extinction had no such effect. Infusion of the $\beta$-adrenergic receptor $(\beta \mathrm{AR})$ inhibitor propranolol and glucocorticoid receptor (GR) inhibitor RU486 into the CA1 area of the dorsal hippocampus before novelty exposure blocked the effect of novelty on extinction memory. Propranolol prevented activation of the hippocampal PKA-CREB pathway, and RU486 prevented activation of the hippocampal extracellular signal-regulated kinase 1/2 (Erk1/ 2)-CREB pathway induced by novelty exposure. These results indicate that the hippocampal $\beta A R-P K A-C R E B$ and GR-Erk1/2-CREB pathways mediate the extinction-enhancing effect of novelty exposure. Infusion of RU486 or the Erk1/2 inhibitor U0126, but not propranolol or the PKA inhibitor Rp-cAMPS, into the CA1 before extinction disrupted the formation of extinction LTM, suggesting that hippocampal GR and Erk1/2 but not $\beta A R$ or PKA play critical roles in this process. These results indicate that novelty promotes extinction memory via hippocampal $\beta \mathrm{AR}$ - and GR-dependent pathways, and Erk1/2 may serve as a behavioral tag of extinction.

Key words: $\beta$-adrenergic receptors; behavioral tag; extinction; glucocorticoid receptors; hippocampus

\section{Introduction}

After being conditioned to a fearful stimulus (unconditioned stimulus, US), a neutral conditioned stimulus (CS) can elicit a fear response (Mueller and Pilzecker, 1900; McGaugh, 2000). However, repeated exposure to a CS without US presentation leads to the extinction of conditioned fear, which has been proposed to be a new CS-no US memory (Pavlov, 1927; Morgan and LeDoux, 1999; Berman and Dudai, 2001; Maren et al., 2013).

Received Jan. 1, 2015; revised April 3, 2015; accepted April 22, 2015.

Author contributions: J.-F.L., J.-H.D., Y.-X.L., H.-S.S., Q.F., Y.-X.X., X.-Y.W., J.-S.W., and L.L. designed research; J.-F.L., C.Y., J.-H.D., W.Y., H.-M.W., S.-Q.M., B.-S.C., N.C., J.S., and C.C. performed research; C.Y. analyzed data; J.L., J.D., and S.-Q.M. wrote the paper.

This work was supported in part by the National Basic Research Program of China (2015CB856400 and 2015CB553503) and Natural Science Foundation of China (31230033, 91432303 and 81221002).

*J.-F.L., C.Y., and J.-H.D. contributed equally to this article.

The authors declare no competing financial interests.

Correspondence should be addressed to either of the following: Lin Lu, Institute of Mental Health, Peking University, 51 Huayuan Bei Road, Beijing 100191, China, E-mail: linlu@bjmu.edu.cn; or Ji-Shi Wang, Affiliated Hospital and School of Pharmacy, Guiyang Medical University, Guiyang 550004, China, E-mail: jswang_yg@yahoo.com.

DOI:10.1523/JNEUROSCI.0005-15.2015

Copyright $\odot 2015$ the authors $\quad 0270-6474 / 15 / 358308-14 \$ 15.00 / 0$
Promoting extinction memory has been considered a strategy for attenuating responsiveness to the original fear memory.

"Synaptic tagging and capture" (STC) has been proposed to contribute to the formation of late-phase LTP (late-LTP; Frey and Morris, 1997; Shires et al., 2012) and long-term memory (LTM; Moncada and Viola, 2007; Ballarini et al., 2009; Moncada et al., 2011), which requires that plasticity-related proteins (PRPs) at other sets of synapses are captured by synaptic taggers at activated synapses (Frey and Morris, 1998). With novelty exposure, early-LTP can become late-LTP in the hippocampus (Li et al., 2003; Straube et al., 2003a; Davis et al., 2004). The influence of novelty on synaptic plasticity requires de novo protein synthesis (Straube et al., 2003b). Novel spatial exploration before learning facilitates memory formation, which has been termed behavioral tagging (Moncada and Viola, 2007; Ballarini et al., 2009; Lu et al., 2011; Moncada et al., 2011; Almaguer-Melian et al., 2012; de Carvalho Myskiw et al., 2014).

Several signaling pathways may be involved in noveltyinduced memory enhancement. The inhibition of hippocampal $\beta$-adrenergic receptors ( $\beta$ ARs) before novelty exposure pre- 
vented novelty-induced LTM formation, indicating that noradrenergic transmission in the hippocampus plays a critical role in the synthesis of PRPs (Moncada et al., 2011). Our previous study showed that $\beta A R$ activation in the CA1 promotes the long-term persistence of fear extinction memory (Chai et al., 2014). Additionally, novelty exposure increased serum concentrations of corticosterone (Quirarte et al., 1997; Kurumaji et al., 2011; Campolongo et al., 2013). Cyclic adenosine monophosphate response element binding protein (CREB) may also be involved in the synthesis of PRPs (Ballarini et al., 2009).

Recent evidence suggests that novelty can make weak extinction become long-lasting extinction, suggesting that behavioral tagging also contributes to the formation of extinction memory (de Carvalho Myskiw et al., 2013). But the extinguished fear returns under some specific conditions (e.g., re-exposure to the US; Pavlov, 1927; Rescorla and Heth, 1975). We hypothesized that novelty might enhance long-lasting extinction memory and decrease the reinstatement of extinguished fear. The effect of novelty-induced arousal depends on the glucocorticoid and noradrenergic systems (Nyakas et al., 1983; Pisa et al., 1988; Chandramohan et al., 2007; Campolongo et al., 2013), but whether these two systems are involved in the effect of novelty exploration on fear extinction is still unknown. The present study used a classical contextual fear-conditioning model to test the effect of novelty on extinction LTM and the reinstatement of extinguished fear and evaluate whether $\beta$ ARs and glucocorticoid receptors (GRs) in hippocampus are involved in this process. The possible behavioral tag of extinction was also investigated.

\section{Materials and Methods}

Subjects. Male Sprague Dawley rats, weighing 240-260 g, were obtained from the Laboratory Animal Center, Peking University Health Science Center. They were housed in groups of five in a temperature-controlled $\left(23 \pm 2^{\circ} \mathrm{C}\right)$ and humidity $(50 \pm 5 \%)$-controlled facility with free access to food and water. They were kept on a reverse $12 \mathrm{~h}$ light/dark cycle. All of the experimental procedures were performed in accordance with the National Institutes of Health Guide for the Care and Use of Laboratory Animals and were approved by the Biomedical Ethics Committee for Animal Use and Protection of Peking University.

Surgery. The rats (weighing 280-300 g when surgery began) were anesthetized with sodium pentobarbital ( $50 \mathrm{mg} / \mathrm{kg}$, i.p.). Guide cannulae (23 gauge; Plastics One) were bilaterally implanted $1 \mathrm{~mm}$ above the CA1 area of the hippocampus. The coordinates were the following: anterior/posterior: $-4.30 \mathrm{~mm}$; medial/lateral: $\pm 2.0 \mathrm{~mm}$; dorsal/ventral: $-2.0 \mathrm{~mm}$ (Paxinos and Watson, 2005). The cannulae were anchored to the skull with stainless-steel screws and dental cement. A stainless-steel stylet blocker was inserted into each cannula to prevent blockage and infection (Lu et al., 2005). The rats were allowed to recover for 1 week after surgery.

Intracranial injections. The $\beta \mathrm{AR}$ blocker propranolol, glucocorticoid receptor (GR) antagonist RU486, PKA inhibitor Rp-cAMPS, and extracellular signal-regulated kinase (Erk1/2) inhibitor U0126 were purchased from Sigma. All of the drugs were freshly prepared and infused into the CA1 area of the dorsal hippocampus in a volume of $1.0 \mu \mathrm{l}$ per side: propranolol ( $0 \mu \mathrm{g} /$ side, $0.3 \mu \mathrm{g} /$ side, or $1.0 \mu \mathrm{g} /$ side), RU486 (0 $\mu \mathrm{g} / \mathrm{side}$, $0.3 \mu \mathrm{g} /$ side, or $1.0 \mu \mathrm{g} /$ side, diluted in 10\% DMSO in saline), Rp-cAMPS ( $0.5 \mu \mathrm{g} /$ side $), \mathrm{U} 0126(0.4 \mu \mathrm{g} /$ side, diluted in $10 \%$ DMSO in saline $)$, and anisomycin $(100 \mu \mathrm{g} / \mu \mathrm{l}$, diluted in saline; Moncada et al., 2011; Chai et al., 2014). The drugs were infused bilaterally over $1 \mathrm{~min}$, and the injection needle was kept in place for an additional $1 \mathrm{~min}$ for drug diffusion ( $\mathrm{Lu}$ et al., 2005; Li et al., 2010).

Histology. The cannula placements were confirmed in $30-\mu$ m-thick sections using Nissl staining under light microscopy. Rats with misplaced cannulae were excluded from the statistical analysis.

Contextual fear memory. The contextual fear-conditioning procedure was based on our previous studies (Yang et al., 2013). The rats were handled for $3 \mathrm{~d}$ before conditioning. On the day of the experiments, they were placed in the conditioning chamber (Beijing Macro Ambition S\&T Development) and allowed to explore the chamber for $2 \mathrm{~min}$, after which they received an electric footshock $(0.8 \mathrm{~mA}, 1 \mathrm{~s})$. The $2 \mathrm{~min} / 1 \mathrm{~s}$ procedure was repeated a total of three times, and the rats were allowed to explore the conditioning chamber for an additional $1 \mathrm{~min}$. After removing the rats from the chambers, the chambers were cleaned with $75 \%$ alcohol to eliminate any residual odor. Two days after the context fear conditioning, the rats were exposed to the training chamber for 30 min without any footshock for extinction. An extinction LTM 1 test and LTM 2 test were conducted by exposing the rats to the conditioning chamber for 5 min without footshock, 2 and $7 \mathrm{~d}$ after extinction, respectively. A footshock was given $1 \mathrm{~d}$ after the second extinction LTM test to reinstate extinguished fear (Haaker et al., 2013). The reinstatement test was conducted $24 \mathrm{~h}$ later. All of the experimental sessions were video recorded for offline analysis. Freezing behavior was defined as the lack of all movement, with the exception of respiration.

Open field. The open field (OF) apparatus was a $75 \mathrm{~cm}$ wide $\times 75 \mathrm{~cm}$ long $\times 45 \mathrm{~cm}$ high arena with brown plywood walls and a wooden floor. The floor was divided into 25 equal $15 \times 15 \mathrm{~cm}$ squares by black lines. The rats were placed in the box to explore the novel environment for 5 min and then returned to their home cage. To familiarize the rats with the arena, they were placed in the arena for $30 \mathrm{~min} 1 \mathrm{~d}$ before the experiment (Moncada and Viola, 2006; Ballarini et al., 2009).

Elevated plus maze. The elevated plus maze test was based on our previous studies (Suo et al., 2013). The entire test was conducted under dim light conditions. Each rat was first placed in the central zone of the elevated plus maze and allowed to freely explore it for $5 \mathrm{~min}$. The number of entries into and time spent (in seconds) on the open arms were recorded by two independent observers who were blind to the animal groups.

Locomotor activity test. Locomotor activity was measured with an automated video-tracking system (DigBehv-LM4; Shanghai Jiliang Software Technology), which had been used in our previous studies (Sun et al., 2013). A monochrome video camera was mounted on top of each chamber. All of the chambers were connected to a computer. The video files (stored on the computer) were analyzed using DigBehv analysis software. Locomotor activity is expressed as the total distance traveled during the 5 min test.

Western blot assays. The Western blot method was based on our previous studies (Lu et al., 2005; Xue et al., 2012; Ren et al., 2013). After decapitation, the brains were rapidly extracted and frozen in $-60^{\circ} \mathrm{C}$ $\mathrm{N}$-hexane. The brains were then transferred to a $-80^{\circ} \mathrm{C}$ freezer. Bilateral tissue punches ( 16 gauge) of the CA1 were placed in a $1.5 \mathrm{ml}$ microtube and homogenized with ice-cold RIPA lysis buffer (Beyotime Biotechnology). The protein concentrations of all of the samples were determined using the BCA assay kit (Beyotime Biotechnology). Four times loading buffer ( $16 \%$ glycerol, $20 \%$ mercaptoethanol, $2 \%$ SDS, and $0.05 \%$ bromophenol blue) was added to each sample (3:1, sample: loading buffer) before being boiled for $3 \mathrm{~min}$. The samples were cooled and subjected to SDS-PAGE ( $10 \%$ acrylamide/ $0.27 \% N, N^{\prime}$-methylenebisacryalamide resolving gel) for $\sim 40 \mathrm{~min}$ at $80 \mathrm{~V}$ in stacking gel and $\sim 1 \mathrm{~h}$ at $120 \mathrm{~V}$ in resolving gel. The proteins were electrophoretically transferred to Immobilon-P transfer membranes (Millipore) at $250 \mathrm{~mA}$ for $2.5 \mathrm{~h}$. The membranes were washed with Tris-buffered saline plus $0.05 \%$ Tween 20 , $\mathrm{pH} 7.4,(\mathrm{TBST})$ and then dipped in blocking buffer (5\% BSA in TBST) overnight at $4^{\circ} \mathrm{C}$. The next day, the membranes were incubated for $1 \mathrm{~h}$ at room temperature on an orbital shaker with anti-brain-derived neurotrophic factor (BDNF) antibody (1:1000; Abcam), anti-pPKA antibody, anti-PKA antibody, anti-pErk1/2 antibody, anti-Erk1/2 antibody, anti-pCREB antibody, anti-CREB antibody (1:200; Santa Cruz Biotechnology), or anti- $\beta$-actin antibody (1:1000; Santa Cruz Biotechnology) in TBST plus 5\% BSA. After three 5 min washes in TBST buffer, the blots were incubated for $45 \mathrm{~min}$ at room temperature on a shaker with horseradish peroxidase-conjugated secondary antibody (goat anti-mouse IgG for $\beta$-actin, and goat anti-rabbit IgG for the others; Santa Cruz Biotechnology) diluted 1:5000 in blocking buffer. The blots were then washed three times for $5 \mathrm{~min}$ each in TBST and incubated with a layer of Super Signal Enhanced chemiluminescence substrate (Detection Reagents 1 and 2, 1:1 ratio; Applygen Technologies). Band intensities were quantified using Quantity One software (version 4.4.0; Bio-Rad). 


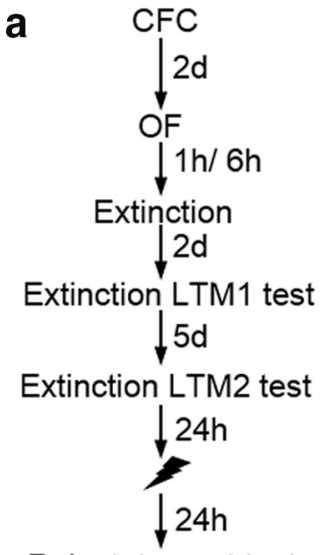

Reinstatement test

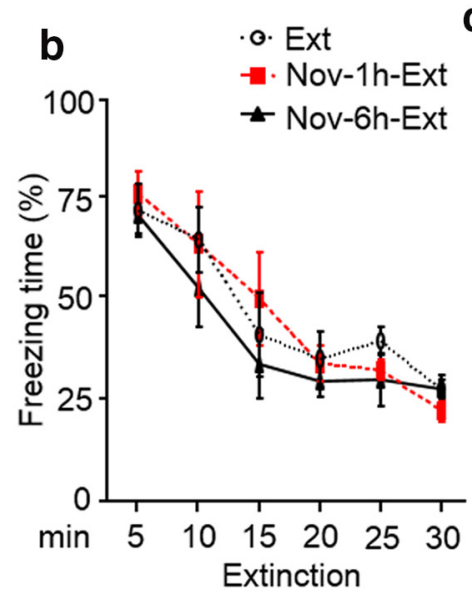

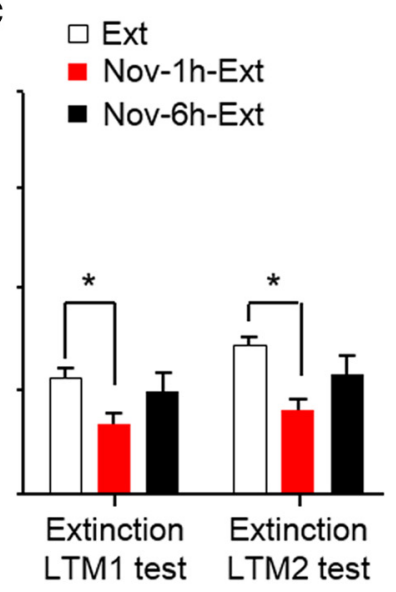

g

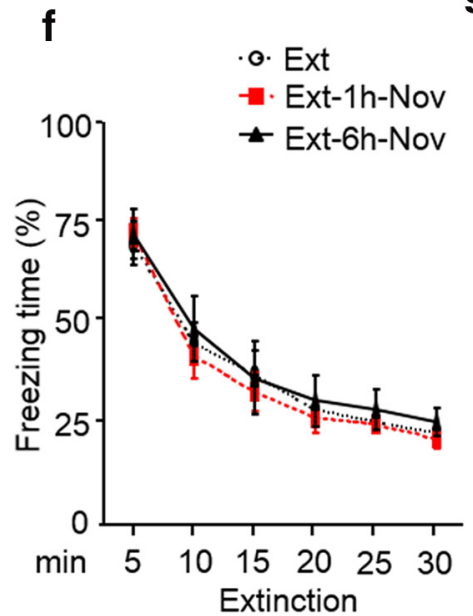

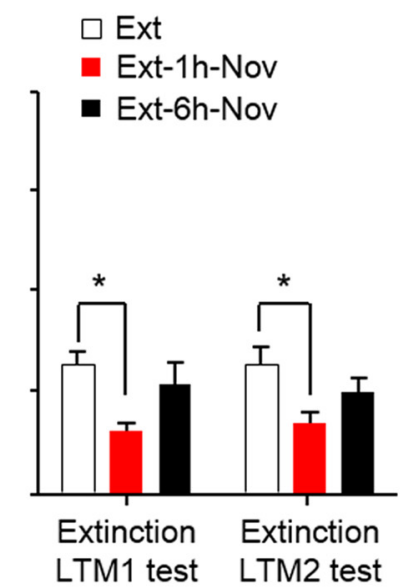

d

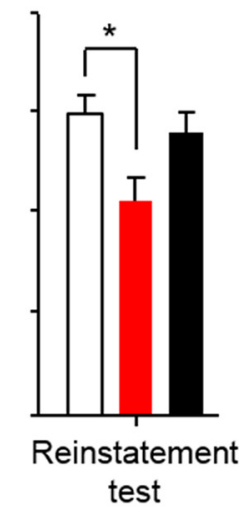

e

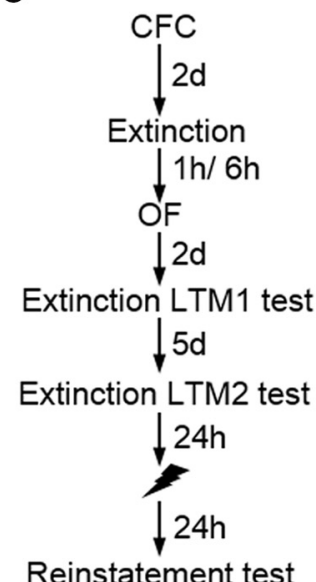

h

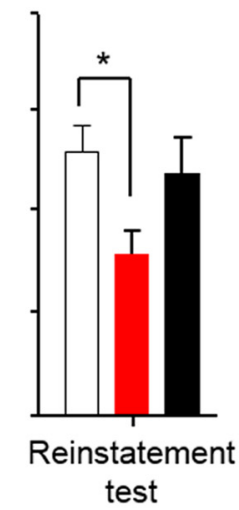

i

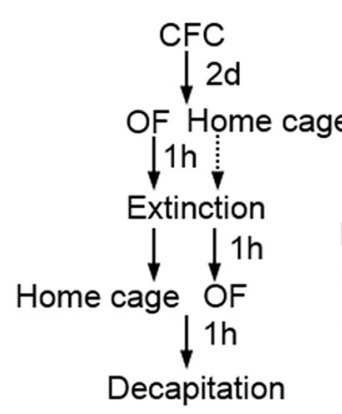
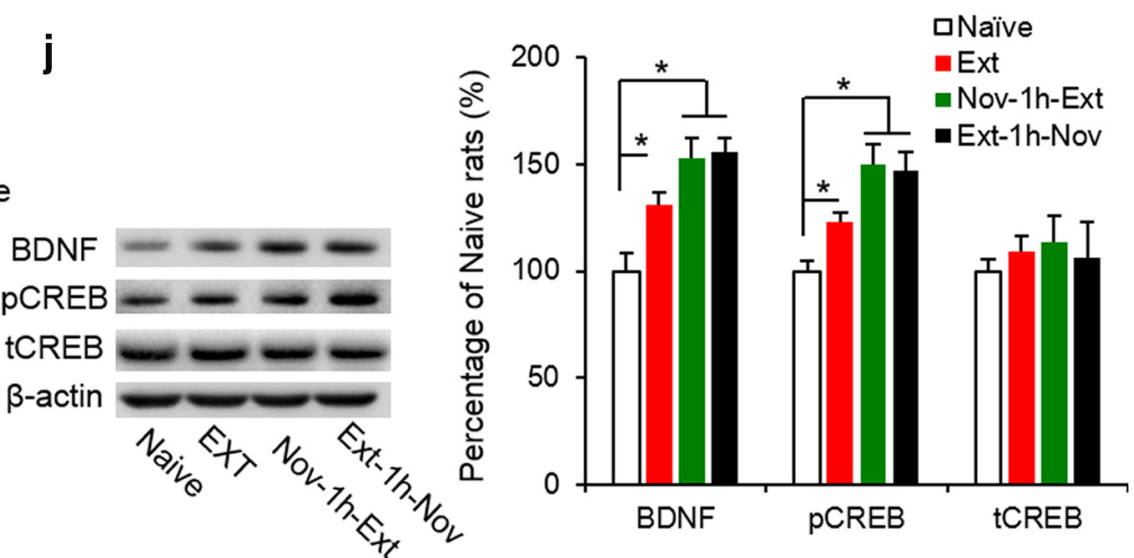

Figure 1. Exposure to the $0 \mathrm{~F} 1 \mathrm{~h}$ before or after extinction (Ext) enhances extinction LTM and reduces reinstatement. $\boldsymbol{a}, \boldsymbol{e}$, Experimental time line. Rats were placed into the $0 \mathrm{~F}$ for 5 min exploration $1 \mathrm{~h}$ or $6 \mathrm{~h}$ before or after extinction. Extinction memory was tested 2 and $7 \mathrm{~d}$ later. One day after the second extinction LTM test, a footshock $(0.8 \mathrm{~mA}, 1 \mathrm{~s})$ was given, and fear reinstatement was tested $1 \mathrm{~d}$ later ( $n=8-9$ per group). $\boldsymbol{b}, \boldsymbol{f}$, OF exploration before or after extinction had no effect on extinction acquisition. $\boldsymbol{c}, \boldsymbol{g}$, Exposure to the $0 \mathrm{~F} 1 \mathrm{~h}$ before or after extinction promoted extinction LTM 2 and $7 \mathrm{~d}$ after extinction. $\boldsymbol{d}, \boldsymbol{h}$, Reinstatement was reduced by $\mathrm{OF}$ exploration $1 \mathrm{~h}$ before or after extinction. $\boldsymbol{i}$, Time line and representative Western blots. The rats were exposed to the $0 \mathrm{~F} 1 \mathrm{~h}$ before or after extinction and decapitated $2 \mathrm{~h}$ after extinction ( $n=6-7$ per group). $j$, Novelty (Nov)-promoted extinction induced the activation of BDNF and CREB in the hippocampus. Data are expressed as mean $\pm S E M ;{ }^{*} p<0.05$. CFC, contextual fear conditioning; $p$ CREB, phosphorylated CREB; tCREB, total CREB.

Statistical analysis. The data are expressed as mean \pm SEM. The statistical analyses were performed using Prism 5 software (GraphPad). Repeat-measures ANOVA was conducted for the extinction, extinction LTM, and locomotor activity data. One-way ANOVA was conducted for the reinstatement, elevated plus maze, and Western blot data. Significant effects in the ANOVAs were followed by the Bonferroni post hoc test. Values of $p<0.05$ were considered statistically significant.

\section{Results}

Novelty within a restricted time window enhances contextual fear extinction, reduces fear reinstatement, and induces BDNF and CREB activation

We first measured the effect of novelty (i.e., exposure to the OF) on contextual extinction LTM and reinstatement. To test whether ex- 


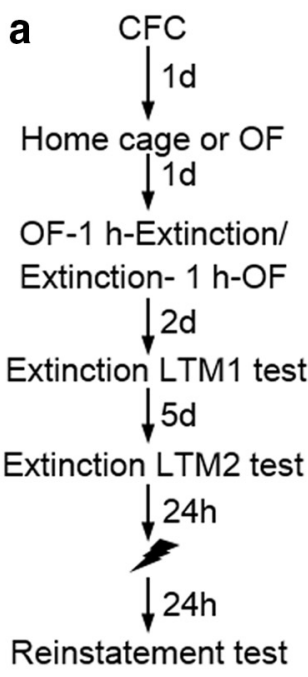

e

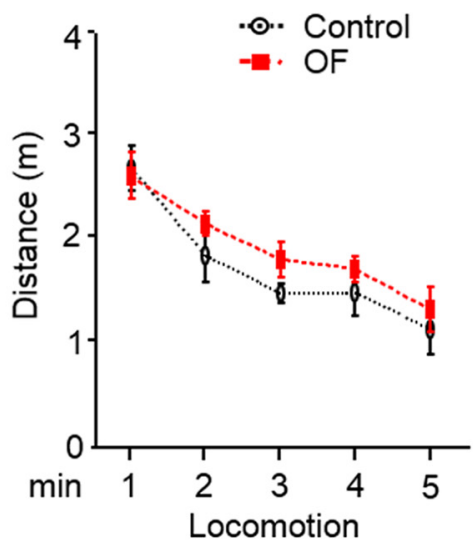

b

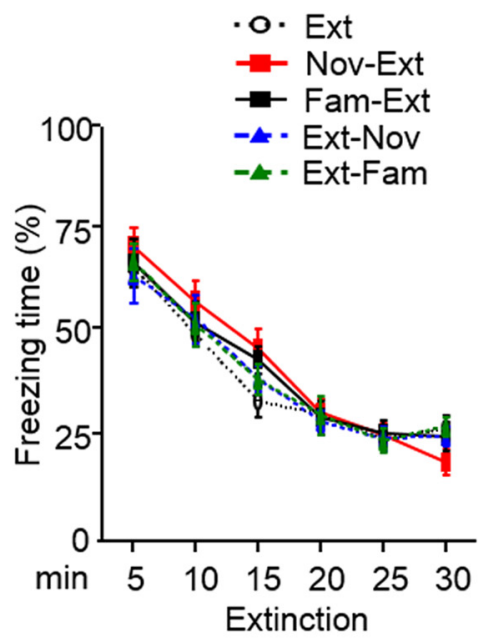

c

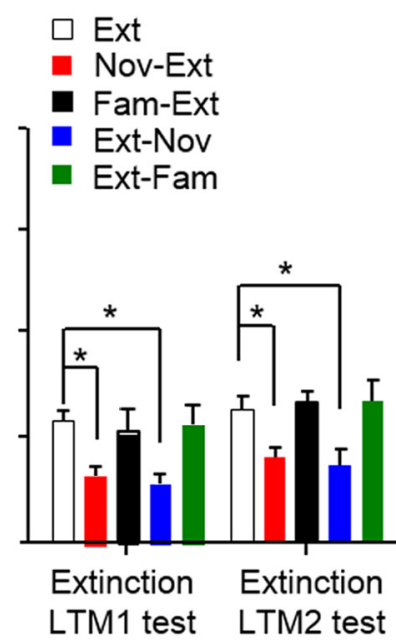

d

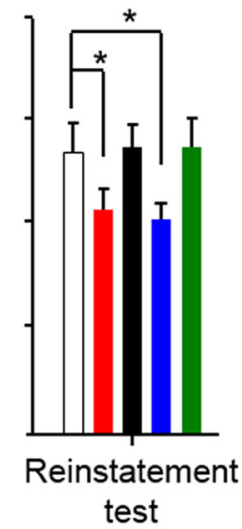

f

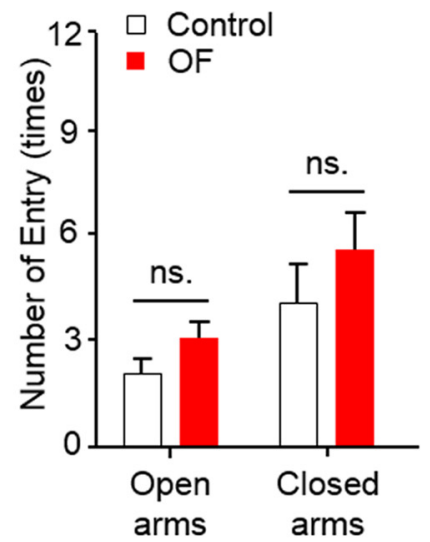

g

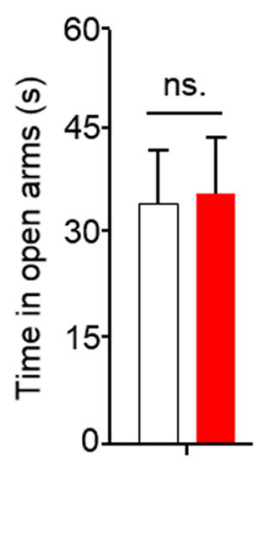

Figure 2. Exposure to the novel but not familiar $0 \mathrm{~F}$ enhances extinction LTM and reduces reinstatement. $\boldsymbol{a}$, Experimental time line. To familiarize the rats with the $0 \mathrm{~F}$, they were allowed to freely explore the apparatus for $30 \mathrm{~min} 1 \mathrm{~d}$ before extinction (Ext). The $0 \mathrm{~F}$ was presented again $1 \mathrm{~h}$ before or after extinction. Extinction LTM and reinstatement were then tested ( $n=8-9$ per group). $\boldsymbol{b}$, Exposure to the novel (Nov) or familiar (Fam) OF did not affect extinction acquisition. c, Neither pre-extinction nor post-extinction exploration of the familiar $0 \mathrm{~F}$ affected extinction LTM 2 and $7 \mathrm{~d}$ after extinction. $\boldsymbol{d}$, Exposure to the familiar $\mathrm{OF}$ had no effect on fear reinstatement. $\boldsymbol{e}, 0 \mathrm{~F}$ exploration did not alter locomotor activity in a 5 min test. In the elevated plus maze, rats that explored the $0 \mathrm{~F}$ exhibited no differences from control rats in the number of entries into the open or closed arms $(\boldsymbol{f})$ or time spent in the open arms $(\boldsymbol{g})$. Data are expressed as mean $\pm \mathrm{SEM} ;{ }^{*} p<0.05$. CFC, contextual fear conditioning.

posure to the OF before extinction affects extinguished fear, two groups of rats were exposed to the OF $1 \mathrm{~h}$ or $6 \mathrm{~h}$ before extinction (Nov-1 h-Ext and Nov-6 h-Ext). A control group of rats underwent extinction without OF exploration (Ext; $n=8-9$ per group; Fig. 1a). Exposure to the OF did not affect the acquisition of extinction $\left(F_{(10,110)}=0.56, p>0.05\right.$; Fig. $\left.1 b\right)$. Repeatedmeasures ANOVA, with Group as the between-subject factor and Test (extinction LTM 1 and 2 tests) as the within-subject factor, was conducted on the extinction LTM data. The ANOVA revealed no Group $\times$ Test interaction $\left(F_{(2,22)}=0.23, p>0.05\right)$, but an effect of Group was observed $\left(F_{(2,22)}=12.06, p<0.001\right)$. The Bonferroni post hoc test revealed differences between the Nov-1 h-Ext and Ext groups in both memory tests conducted $2 \mathrm{~d}(t=$ $2.45, p<0.05)$ and $7 \mathrm{~d}(t=3.46, p<0.01$; Fig. $1 c)$ after extinction, suggesting that novelty presented $1 \mathrm{~h}$ before extinction enhanced extinction LTM, and this effect persisted for at least $7 \mathrm{~d}$ after extinction. OF exploration $1 \mathrm{~h}$ before extinction also reduced fear reinstatement $\left(F_{(2,24)}=3.71, p<0.05\right.$; Nov-1 h-Ext vs Ext: $t=2.70, p<0.05$; Fig. $1 d)$. To test whether exposure to the $\mathrm{OF}$ after extinction affects the extinguished fear, three groups of rats were also included (Ext; Ext-1 h-Nov; Ext-6 h-Nov; $n=8-9$ per group; Fig. 1e). Extinction acquisition was similar between all three groups $\left(F_{(10,110)}=0.13, p>0.05\right.$; Fig. $\left.1 f\right)$. The ANOVA revealed no Group $\times$ Test interaction $\left(F_{(2,22)}=0.11, p>0.05\right)$, but an effect of Group was observed $\left(F_{(2,22)}=8.29, p<0.01\right)$. The Bonferroni post hoc test revealed differences between the Ext-1 h-Nov and Ext groups in the memory tests both $2 \mathrm{~d}(t=2.98, p<$ $0.01)$ and $7 \mathrm{~d}(t=2.70, p<0.05$; Fig. $1 g)$ after extinction. Freezing time in the reinstatement test was decreased by exposure to the OF $1 \mathrm{~h}$ after extinction $\left(F_{(2,24)}=4.64, p<0.05\right.$; Ext- $1 \mathrm{~h}-\mathrm{Nov}$ vs Ext: $t=2.87, p<0.05$; Fig. $1 h)$. These results indicate that novelty exploration $1 \mathrm{~h}$ before or after extinction enhanced extinction LTM and reduced fear reinstatement. We then examined the effects of novelty on the protein levels of BDNF and pCREB, which are critical for the consolidation of extinction memory (Chhatwal et al., 2006; Monti et al., 2006; Heldt et al., 2007). The OF was presented $1 \mathrm{~h}$ before or after extinction. The rats were decapitated $2 \mathrm{~h}$ after extinction. Four groups of rats were included (Naive, Ext, Nov-1 h-Ext, and Ext-1 h-Nov; $n=6-7$ per group; Fig. 1i). The levels of BDNF and pCREB were elevated by extinction and further augmented by exposure to novelty before extinction $\left(F_{(3,27)}=21.43, p<0.001\right.$; Ext vs Nov-1 h-Ext: $t=$ 

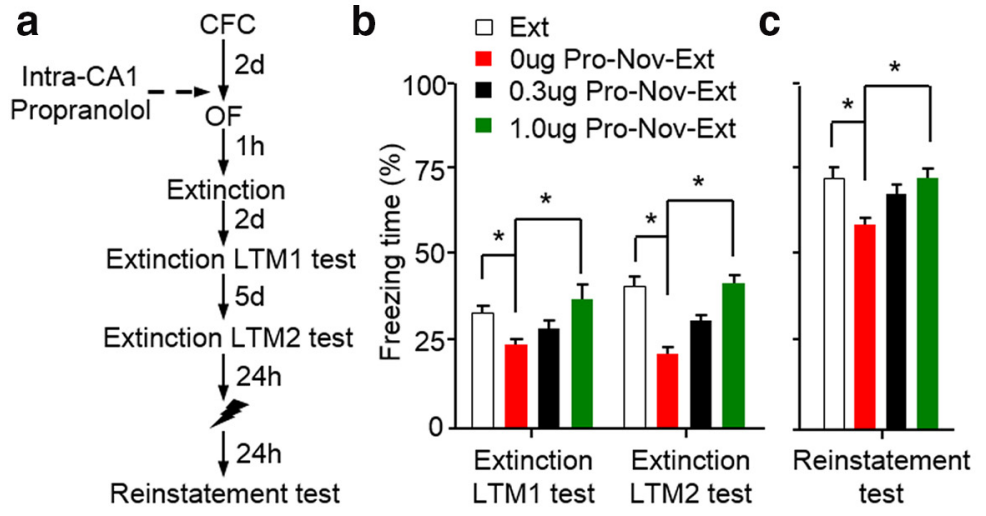

d

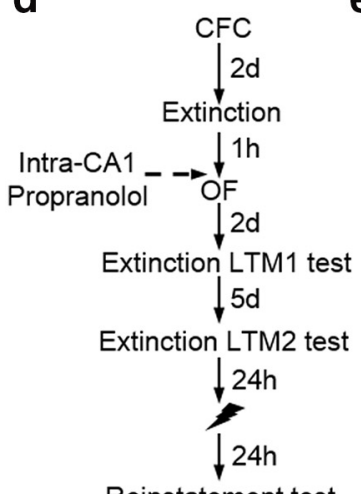

e

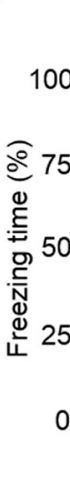

$\square$ Ext

- Ext-Oug Pro-Nov

${ }^{100}$ - Ext-0.3ug Pro-Nov

Ext-1.0ug Pro-Nov

Reinstatement test f

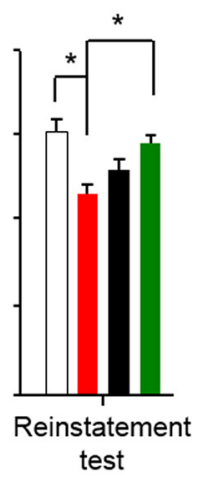

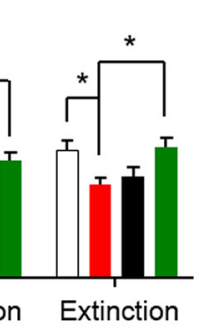

LTM2 test g

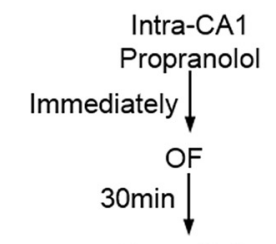

Decapitation $\beta$-actin

i
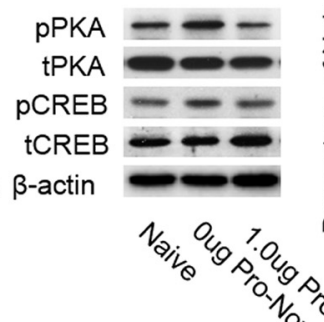

1 test $\square$ Naive

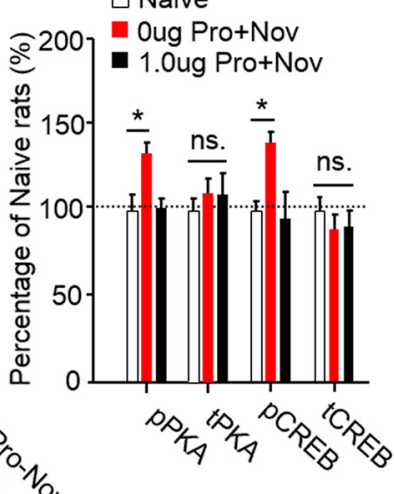

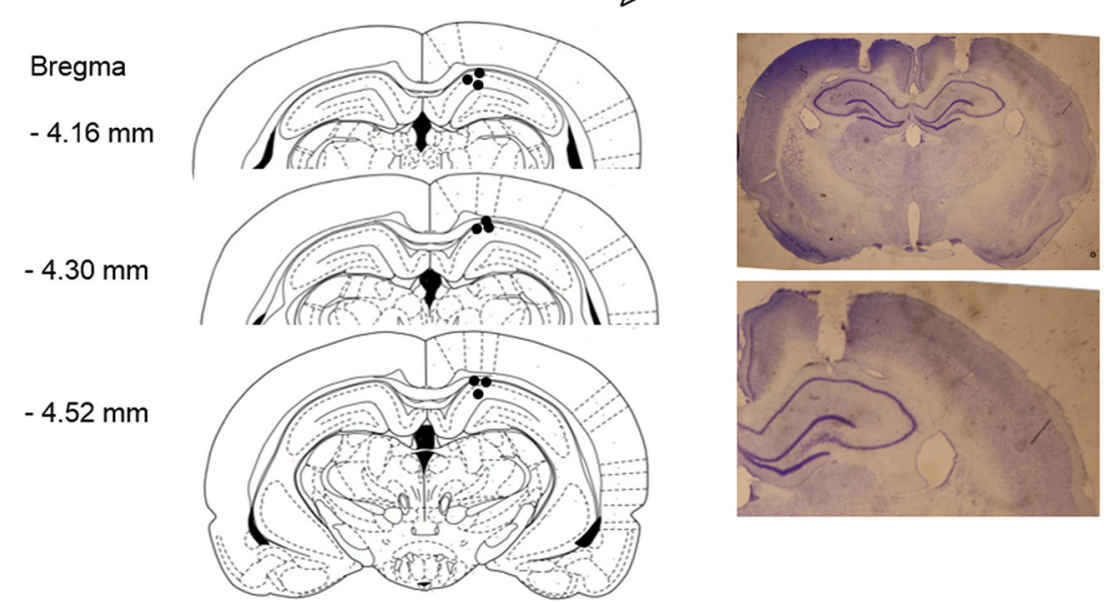

Figure 3. Inhibition of hippocampal $\beta$-adrenergic receptors blocks the extinction-enhancing effect of novelty (Nov). $\boldsymbol{a}, \boldsymbol{d}$, Propranolol (Pro) at doses of $0,0.3$, and $1.0 \mu \mathrm{g}$ was micro-infused into the $\mathrm{CA} 1$ area of the dorsal hippocampus before $0 \mathrm{~F}$ exposure. The $O F$ was presented $1 \mathrm{~h}$ before or after extinction (Ext). Extinction LTM and reinstatement were then tested $(n=9-10$ per group). $\boldsymbol{b}, \boldsymbol{e}$, Pretreatment with $1.0 \mu \mathrm{g}$ propranolol prevented the enhancement of extinction LTM induced by novelty exploration $1 \mathrm{~h}$ before or after extinction. $\boldsymbol{c}, \boldsymbol{f}$, The decrease in freezing time in the reinstatement test induced by OF exploration was also

$3.173, p<0.05 ; F_{(3,23)}=24.57, p<0.001 ;$ Ext vs Nov-1 h-Ext: $t=3.565, p<0.05)$ and after extinction $\left(F_{(3,23)}=21.43, p<\right.$ 0.001 ; Ext vs Ext-1 h-Nov: $t=3.449, p<$ $0.05 ; F_{(3,23)}=24.57, p<0.001 ;$ Ext vs Nov-1 h-Ext: $t=3.361, p<0.05$; Fig. $1 j$ ). These results indicate that hippocampal BDNF and CREB may act as behavioral tags of extinction memory and promote the consolidation of extinction memory.

\section{Novel but not familiar environment exploration promotes extinction LTM}

To test whether the extinction-enhancing effect was caused by the novel feature of the $\mathrm{OF}$, the rats were allowed to explore the $\mathrm{OF}$ for $30 \mathrm{~min} 1 \mathrm{~d}$ before extinction to familiarize them with the environment (Moncada and Viola, 2006). Five groups were included: rats that explored the familiar OF $1 \mathrm{~h}$ before or after extinction (Fam-Ext, Ext-Fam), rats that explored the novel OF $1 \mathrm{~h}$ before or after extinction (Nov-Ext, Ext-Nov), and rats that underwent extinction without OF exploration (Ext; $n=8-9$ per group; Fig. $2 a$ ). Extinction acquisition was similar between all three groups $\left(F_{(20,190)}=0.99, p>0.05\right.$; Fig. $2 b$ ). The repeated-measures ANOVA of the extinction LTM data revealed no Group $\times$ Test interaction $\left(F_{(4,38)}=0.12\right.$, $p>0.05)$, but an effect of Group was observed $\left(F_{(4,38)}=7.10, p<0.001\right)$. The Bonferroni post hoc test showed that the familiar OF had no effect on extinction LTM (all $p s>0.05$; Fig. $2 c$ ). Fear reinstatement was also decreased in the novel OF exploration groups but not familiar OF exploration groups $\left(F_{(4,42)}=7.02, p<\right.$ 0.001; Bonferroni post hoc test; Ext vs Fam-Ext: $t=0.51, p>0.05$; Ext vs NovExt: $t=4.24, p<0.01$; Ext vs Ext-Fam: $t=$ $0.71, p>0.05$; Ext vs Ext-Nov: $t=3.29$, $p<0.05$; Fig. $2 d$ ).

We then investigated whether the novel OF affects locomotion or anxietylike behavior, which can influence freezing behavior in rats. The rats were placed in the OF or home cage $1 \mathrm{~h}$ before the locomotion test or elevated plus maze test ( $n=8$ per group). Exposure to the OF did

\section{$\longleftarrow$}

blocked by propranolol. $\boldsymbol{g}$, Time line and representative Western blots. Saline or propranolol $(1.0 \mu \mathrm{g})$ was micro-infused into the $\mathrm{CA} 1$ before $\mathrm{OF}$ exposure. The rats were decapitated 30 min after OF exploration ( $n=6$ per group). $\boldsymbol{h}$, Propranolol prevented the increase in phosphorylated PKA (PPKA) and phosphorylated CREB ( $p$ CREB) induced by novelty. Data are expressed as mean \pm SEM; ${ }^{*} p<0.05$. $i$, Schematic representation and photomicrographs of cannula placements in the CA1 area of the dorsal hippocampus. CFC, contextual fear conditioning tCREB, total CREB; tPKA, total PKA. 


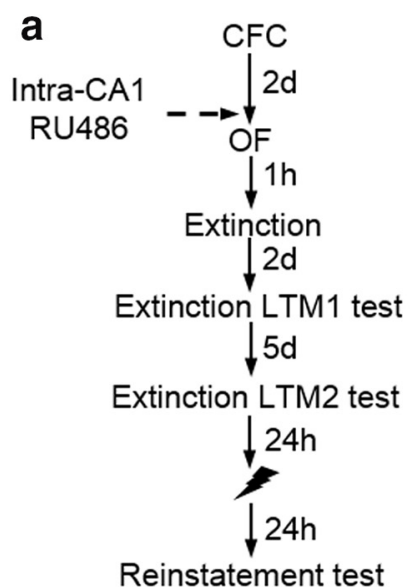

b

d

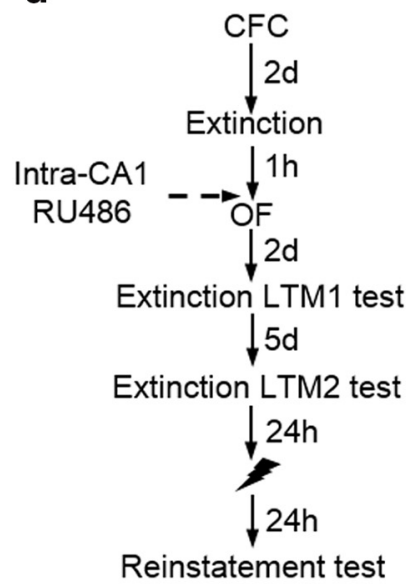

g

e
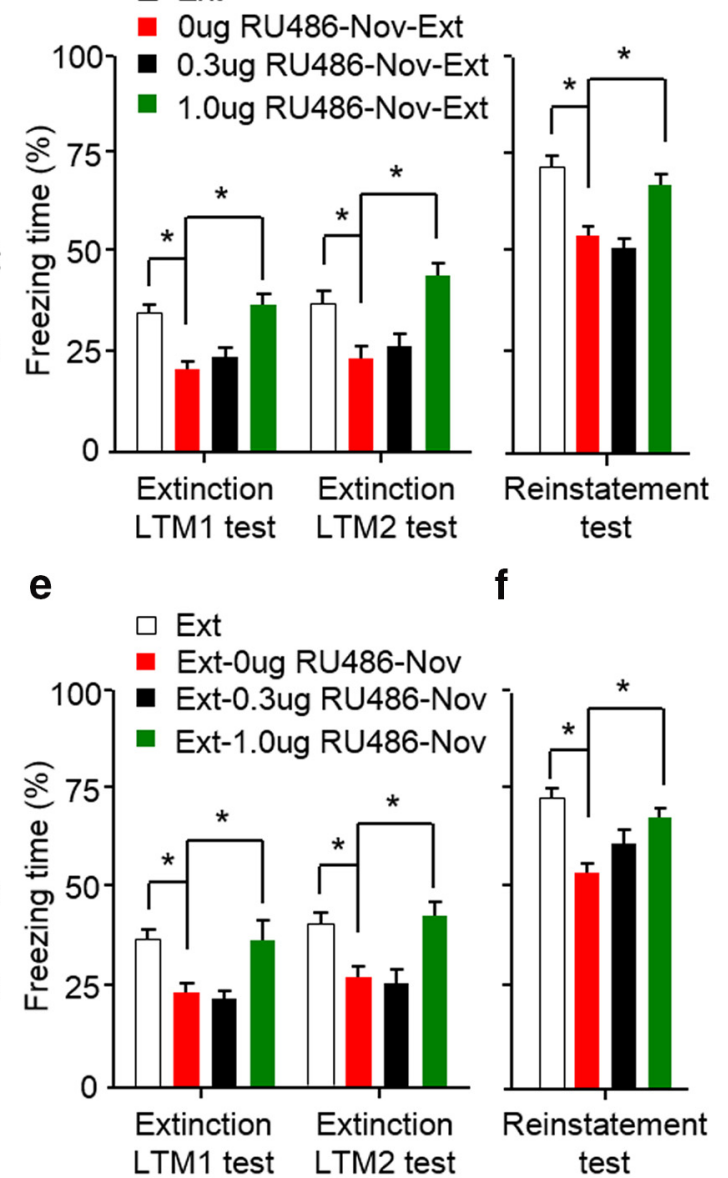

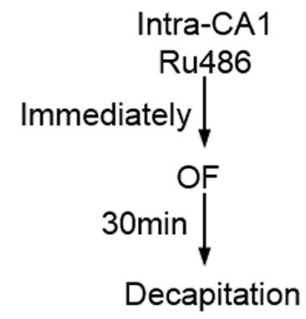

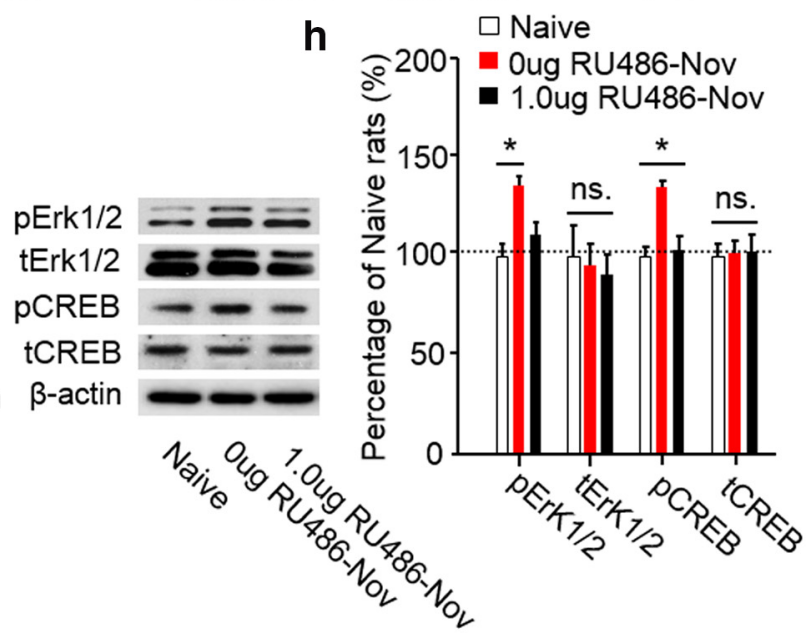

Figure 4. Inhibition of hippocampal GRs prevents the extinction-enhancing effect of novelty (Nov). $\boldsymbol{a}, \boldsymbol{d}$, RU486 at doses of 0 , 0.3 , and $1.0 \mu \mathrm{g}$ was micro-infused into the CA1 before $0 \mathrm{~F}$ exposure. The $0 \mathrm{~F}$ was presented $1 \mathrm{~h}$ before or after extinction (Ext). Extinction LTM and reinstatement were then tested ( $n=9-10$ per group). $\boldsymbol{b}, \boldsymbol{e}, \mathrm{RU} 486$ at a dose of $1.0 \mu \mathrm{g}$ blocked the promotion of extinction LTM induced by novelty. $\boldsymbol{c}, \boldsymbol{f}, \mathrm{RU} 486$ also blocked the novelty-induced reduction of freezing time in the reinstatement test. $\boldsymbol{g}$, Time line and representative Western blots. Saline or RU486 (1.0 $\mu \mathrm{g})$ was micro-infused into the CA1 before exposure to the OF. The rats were decapitated 30 min after $0 F$ exploration ( $n=6$ per group). $\boldsymbol{h}$, RU486 prevented the increase in phosphorylated PKA (pPKA) and phosphorylated CREB (pCREB) induced by novelty. Data are expressed as mean $\pm S E M$; ${ }^{*} p<0.05$. CFC, contextual fear conditioning; tCREB, total CREB; pErk1/2, phosphorylated Erk1/2, total Erkl/2.

not affect the distance traveled $\left(F_{(4,56)}=0.44, p>0.05\right.$; Fig. $\left.2 e\right)$, number of entries into the open arms (two-tailed $t$ test; $t=1.61$, $p>0.05)$, number of entries into the closed arms $(t=0.95, p>$ 0.05 ; Fig. $2 f)$, or time spent on the open arms $(t=0.12, p>0.05$; Fig. $2 g$ ), suggesting that exposure to the OF did not affect loco- motion or anxiety-like behavior. These results indicate that the enhancement of extinction LTM and reduction of reinstatement were likely attributable to the novel feature of the OF.

\section{Hippocampal $\beta$ ARs are involved in novelty-induced enhancement of extinction}

Exposure to a novel environment causes emotional arousal, which may depend on glucocorticoids and epinephrine, two important stress hormones that are involved in memory modulation (McIntyre et al., 2012). To examine the role of hippocampal $\beta A R s$ in the extinction-enhancing effect of novelty, the $\beta A R$ inhibitor propranolol $(0,0.3$, and $1.0 \mu \mathrm{g})$ was microinfused into the CA1 area of the hippocampus immediately before exposure to the OF. To determine the effect of propranolol on the extinction-enhancing effect of novelty exposure $1 \mathrm{~h}$ before extinction, four groups of rats were included (Ext, $0 \mu \mathrm{g}$ Pro-Nov-Ext, $0.3 \mu \mathrm{g}$ Pro-NovExt, and $1.0 \mu \mathrm{g}$ Pro-Nov-Ext; $n=10$ per group; Fig. 3a). A repeated-measures ANOVA was conducted to analyze the extinction LTM data, revealing an effect of Group $\left(F_{(3,36)}=15.72, p<0.001\right)$. The Bonferroni post hoc test revealed differences between the $1.0 \mu \mathrm{g}$ ProNov-Ext and $0 \mu \mathrm{g}$ Pro-Nov-Ext groups in the memory tests $2 \mathrm{~d}(t=3.85, p<$ $0.001)$ and $7 \mathrm{~d}(t=5.88, p<0.001)$ after extinction (Fig. $3 b$ ). The decrease in freezing time in the reinstatement test induced by OF exploration before extinction was also blocked by $1.0 \mu \mathrm{g}$ propranolol $\left(F_{(3,39)}=5.73, p<0.01\right.$; Bonferroni post hoc test: $1.0 \mu \mathrm{g}$ ProNov-Ext vs $0 \mu \mathrm{g}$ Pro-Nov-Ext, $t=3.57$, $p<0.01$; Fig. $3 c$ ). To test the effect of propranolol on the extinctionenhancing effect of novelty presented after extinction, four groups of rats were included (Ext, Ext-0 $\mu \mathrm{g}$ Pro-Nov, Ext$0.3 \mu \mathrm{g}$ Pro-Nov, and Ext-1.0 $\mu \mathrm{g}$ ProNov; $n=9$ per group; Fig. $3 d$ ). A repeated-measures ANOVA was conducted to analyze the extinction LTM data, revealing an effect of Group $\left(F_{(3}\right.$, $\left.\left.{ }_{32}\right)=10.90, p<0.001\right)$. The Bonferroni post hoc test revealed differences between the $1.0 \mu \mathrm{g}$ Pro-Ext-Nov and $0 \mu \mathrm{g}$ Pro-Ext-Nov groups in the memory tests $2 \mathrm{~d}(t=3.13, p<0.01)$ and $7 \mathrm{~d}(t=$ 3.04, $p<0.001$ ) after extinction (Fig. $3 e)$. The one-way ANOVA revealed an effect in the reinstatement test $\left(F_{(3,35)}=7.27, p<0.01\right)$. The post hoc analysis showed that freezing time was increased in the $1.0 \mu \mathrm{g}$ Pro-ExtNov group compared with the $0 \mu \mathrm{g}$ Pro-Ext-Nov group $(t=$ 4.23, $p<0.01$; Fig. $3 f)$. 
We then determined the possible signaling pathway that underlies the disrupting effect of propranolol on the enhancement of extinction induced by novelty. Saline or $1.0 \mu \mathrm{g}$ propranolol was infused into the CA1 before OF exploration. The rats were decapitated 30 min after exposure to the OF $(n=6$ per group; Fig. $3 \mathrm{~g}$ ). Propranolol blocked the OF-induced activation of PKA $\left(F_{(2,17)}=7.14, p<0.01\right)$ and CREB $\left(F_{(2,17)}=6.02, p<0.05\right.$; Fig. $\left.3 h\right)$ in the CA1. Altogether, these results indicate that the extinction-enhancing effect of novelty exploration requires the hippocampal $\beta$ AR-PKA-CREB pathway. The locations of the cannula tips are shown in Figure $3 i$.

\section{Hippocampal GRs are involved in novelty-induced extinction enhancement}

The role of hippocampal GR in the enhancement of extinction induced by novelty was also investigated. The GR inhibitor RU486 $(0,0.3$, and $1.0 \mu \mathrm{g})$ was micro-infused into the CA1 before OF exploration. To determine the effect of RU486 on the extinction-enhancing effect of novelty presented before extinction, four groups of rats were included (Ext, 0 $\mu \mathrm{g}$ RU486-Nov-Ext, $0.3 \mu \mathrm{g}$ RU486-NovExt, and $1.0 \mu \mathrm{g}$ RU486-Nov-Ext; $n=$ 9-10 per group; Fig. 4a). A repeatedmeasures ANOVA was conducted to analyze the extinction LTM data, revealing an effect of Group $\left(F_{(3,35)}=24.51, p<\right.$ 0.001). The Bonferroni post hoc test revealed differences between the $1.0 \mu \mathrm{g}$ RU486-Nov-Ext and $0 \mu \mathrm{g}$ RU486-Nov-

Ext groups in the memory tests $2 \mathrm{~d}(t=4.04, p<0.001)$ and $7 \mathrm{~d}$ $(t=5.29, p<0.001)$ after extinction (Fig. $4 b)$. The reduction of fear reinstatement induced by $\mathrm{OF}$ exploration before extinction was prevented by $1.0 \mu \mathrm{g} \operatorname{RU} 486\left(F_{(3,38)}=15.54, p<0.001\right.$; Bonferroni post hoc test: Nov-1.0 $\mu \mathrm{g}$ RU486-Ext vs Nov-0 $\mu \mathrm{g}$ RU486-Ext, $t=3.56, p<0.01$; Fig. $4 c$ ). To test the effect of RU486 on the extinction-enhancing effect of OF exploration after extinction, four groups of rats were included (Ext, Ext-0 $\mu \mathrm{g}$ RU486-Nov, Ext-0.3 $\mu \mathrm{g}$ RU486-Nov, and Ext-1.0 $\mu \mathrm{g}$ RU486Nov; $n=9$ per group; Fig. $4 d$ ). A repeated-measures ANOVA was conducted to analyze the extinction LTM data, revealing an effect of Group $\left(F_{(3,32)}=12.46, p<0.001\right)$. The Bonferroni post hoc test revealed differences between the Ext-1.0 $\mu \mathrm{g}$ RU486-Nov and Ext-0 $\mu$ g RU486-Nov groups in the tests conducted $2 \mathrm{~d}(t=2.94$, $p<0.01)$ and $7 \mathrm{~d}(t=3.49, p<0.01)$ after extinction (Fig. $4 e)$. RU486 at a dose of $1.0 \mu \mathrm{g}$ also blocked the decrease in fear reinstatement induced by OF exploration after extinction $\left(F_{(3,35)}=9.41, p<\right.$ 0.001; Bonferroni post hoc test: $1.0 \mu \mathrm{g}$ RU486-Ext-Nov vs $0 \mu \mathrm{g}$ RU486-Ext-Nov, $t=3.63, p<0.01$; Fig. $4 f)$. RU486 also prevented the novelty-induced activation of Erk1/2 $\left(F_{(2,17)}=9.35, p<0.01\right)$ and CREB $\left(F_{(2,17)}=13.20, p<0.001\right.$; Fig. $\left.4 g, h\right)$ in the CA1. These results indicate that the extinction-enhancing effect of novelty exploration requires the hippocampal GR-Erk1/2-CREB pathway.

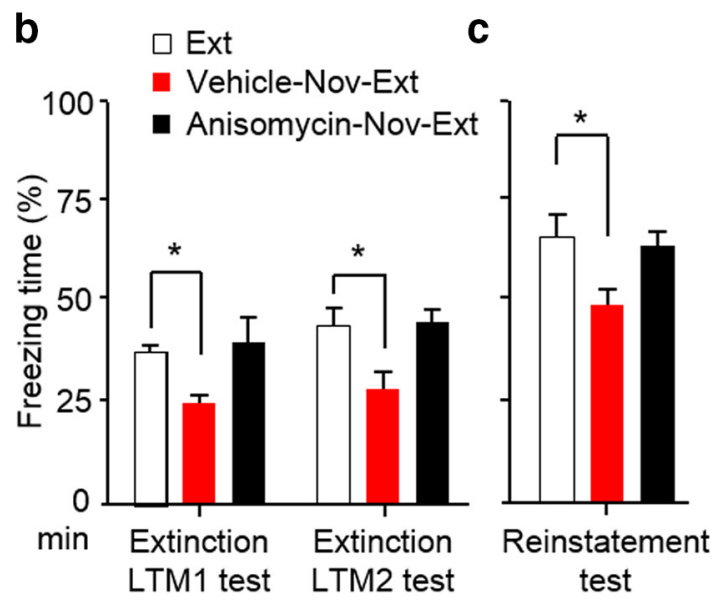

e

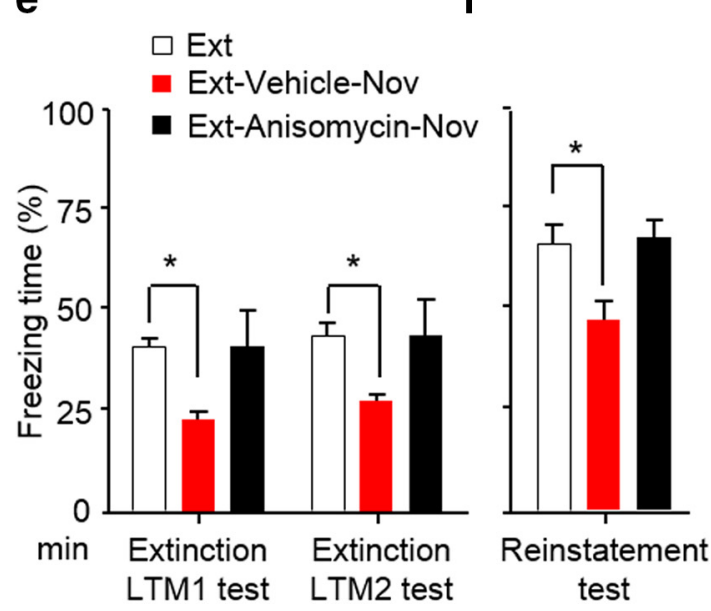

Figure 5. The extinction-enhancing effect of novelty (Nov) requires de novo protein synthesis in the CA1 area of the hippocampus. $\boldsymbol{a}, \boldsymbol{d}$, Anisomycin or saline was micro-infused into the CA1 before OF exploration. The OF was presented $1 \mathrm{~h}$ before or after extinction (Ext). Extinction LTM and reinstatement were then tested ( $n=8-9$ per group). $\boldsymbol{b}, \boldsymbol{e}$, Anisomycin blocked the promotion of extinction LTM induced by novelty exposure. $\boldsymbol{c}, \boldsymbol{f}$, Anisomycin also blocked the novelty-induced reduction of freezing time during the reinstatement test. Data are expressed as mean \pm SEM; ${ }^{*} p<0.05$. CFC, contextual fear conditioning.

Novelty-induced enhancement of extinction requires hippocampal protein synthesis

The actions of both $\beta A R$ and GR require the activation of CREB, which is critical for protein synthesis. We determined whether the enhancement of extinction induced by novelty requires hippocampal de novo protein synthesis after novelty exposure. The protein synthesis inhibitor anisomycin was micro-infused into the CA1 before OF exploration. Three groups of rats were included in the experiment in which novelty was presented before extinction (Ext, Saline-Nov-Ext, and Anisomycin-Nov-Ext; $n=$ 8-9 per group; Fig. 5a). The repeated-measures ANOVA revealed an effect of Group $\left(F_{(2,23)}=11.55, p<0.001\right)$ in the extinction LTM tests. The Bonferroni post hoc test showed that anisomycin blocked the enhancement of extinction induced by novelty $(p<0.05$; Fig. $5 b)$. Moreover, the decrease in fear reinstatement by novelty was also blocked by anisomycin $\left(F_{(2,25)}=\right.$ 4.45, $p<0.05$; Fig. 5c).

Three groups of rats were included in the experiment that assessed the effect of novelty presented after extinction (Ext, ExtSaline-Nov, and Ext-Anisomycin-Nov; $n=8-9$ per group; Fig. $5 d)$. The repeated-measures ANOVA revealed an effect of Group $\left(F_{(2,23)}=4.55, p<0.001\right)$ in the extinction LTM tests. The Bonferroni post hoc test showed that anisomycin blocked the 

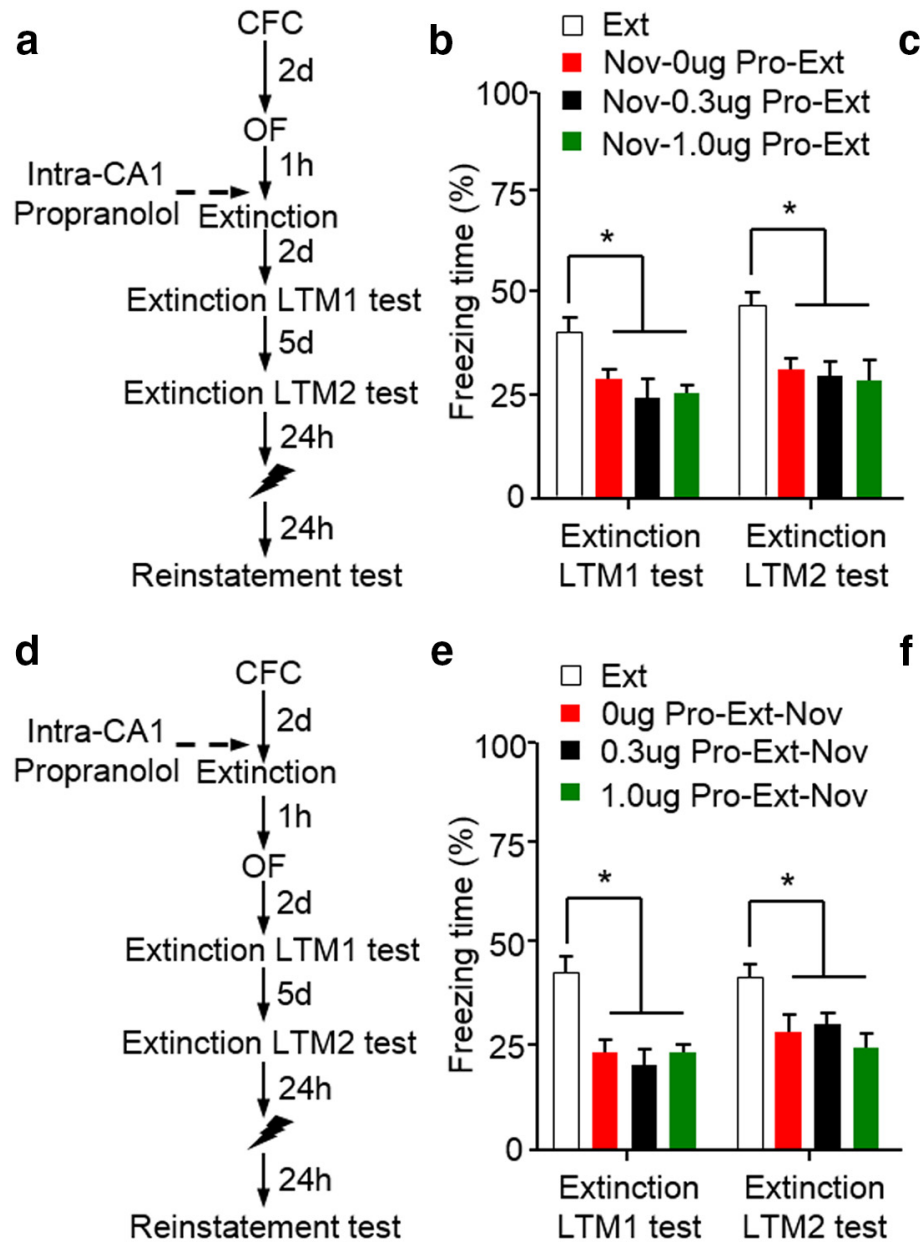

Figure 6. Hippocampal $\beta$ ARs do not serve as a behavioral tag of extinction. $\boldsymbol{a}, \boldsymbol{d}$, The $\beta$ AR inhibitor propranolol (Pro) was micro-infused into the CA1 before extinction. The $0 \mathrm{~F}$ was presented $1 \mathrm{~h}$ before or after extinction (Ext). Extinction LTM and reinstatement were then tested ( $n=8-9$ per group). $\boldsymbol{b}$, $\boldsymbol{c}$, Novelty (Nov) presented before extinction promoted extinction LTM and decreased fear reinstatement, which were not affected by propranolol. $\boldsymbol{e}, \boldsymbol{f}$, Propranolol did not affect the formation of extinction LTM promoted by novelty presented after extinction or the decrease in reinstatement. Data are expressed as mean \pm SEM; ${ }^{*} p<0.05$. CFC, contextual fear conditioning.

enhancement of extinction induced by novelty $(p<0.05$; Fig. $5 e)$. Moreover, the decrease in fear reinstatement induced by novelty was also blocked by anisomycin $\left(F_{(2,25)}=6.16, p<0.01\right.$; Fig. $5 f)$. These results indicate that the extinction-enhancing effect of novelty exploration requires hippocampal de novo protein synthesis.

\section{Hippocampal $\beta$ ARs do not act as a behavioral tag of extinction}

We then tested whether hippocampal $\beta$ ARs are critical for extinction LTM during extinction. Four groups of rats were exposed to novelty and underwent extinction $1 \mathrm{~h}$ later, and propranolol was micro-infused into the CA1 immediately before extinction (Ext, Nov-0 $\mu$ g Pro-Ext, Nov-0.3 $\mu$ g Pro-Ext, and Nov-1.0 $\mu$ g Pro-Ext; $n=8-9$ per group; Fig. $6 a$ ). The repeated-measures ANOVA revealed an effect of Group $\left(F_{(3,30)}=11.49, p<0.001\right)$ in the extinction LTM tests. The Bonferroni post hoc test showed that propranolol had no effect on extinction LTM ( $p>0.05$; Fig. $6 b)$. Moreover, novelty decreased fear reinstatement $\left(F_{(3,34)}=5.07, p<\right.$ 0.01 ), which was not affected by propranolol ( $p>0.05$; Fig. $6 c)$.

When novelty exposure was conducted after the propranolol injection and extinction (Ext, $0 \mu \mathrm{g}$ Pro-Ext-Nov, $0.3 \mu \mathrm{g}$ Pro-Ext-
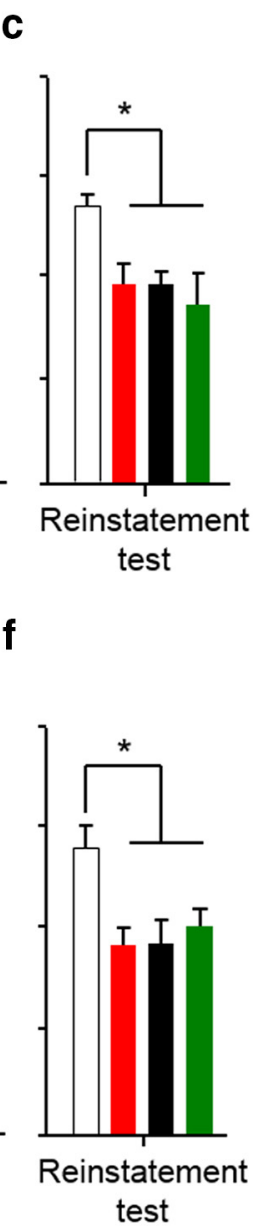

Nov, and $1.0 \mu \mathrm{g}$ Pro-Ext-Nov; $n=8-9$ per group; Fig. $6 d$ ), the repeatedmeasures ANOVA revealed an effect of Group $\left(F_{(3,30)}=11.60, p<0.001\right)$ in the extinction LTM tests. The Bonferroni post hoc test showed that propranolol had no effect on extinction LTM ( $p>0.05$; Fig. $6 e)$. Moreover, novelty decreased fear reinstatement $\left(F_{(3,34)}=5.61, p<0.01\right)$, which was not affected by propranolol $(p>0.05$; Fig. $6 f$ ). The enhancement of extinction induced by novelty did not require hippocampal $\beta$ ARs during extinction, indicating that hippocampal $\beta$ ARs do not act as a behavioral tag of extinction memory.

\section{Hippocampal GRs act as a behavioral} tag of extinction

We then examined the role of hippocampal GR in extinction LTM during extinction. In the experiment that assessed the effect of novelty presented before extinction, four groups of rats were exposed to novelty and then underwent extinction, and RU486 was micro-infused into the CA1 before extinction (Ext, Nov-0 $\mu \mathrm{g}$ RU486-Ext, Nov-0.3 $\mu \mathrm{g}$ RU486-Ext, and Nov-1.0 $\mu$ g RU486-Ext; $n=8-10$ per group; Fig. 7a). The repeated-measures ANOVA revealed an effect of Group $\left(F_{(3,34)}=30.03, p<0.001\right)$ in the extinction LTM tests. The Bonferroni post hoc test showed that RU486 prevented the formation of extinction LTM (both $p<0.05$; Fig. 7b). Moreover, novelty decreased fear reinstatement $\left(F_{(3,36)}=4.08, p<0.05\right)$, which was prevented by RU486 $(p<0.05$; Fig. 7c).

In the experiment that assessed the effect of novelty presented after extinction, four groups of rats were exposed to novelty and then underwent extinction, and RU486 was microinfused into the CA1 before extinction (Ext, $0 \mu \mathrm{g}$ RU486-ExtNov, $0.3 \mu \mathrm{g}$ RU486-Ext-Nov, and $1.0 \mu \mathrm{g}$ RU486-Ext-Nov; $n=$ $8-9$ per group; Fig. $7 d$ ). The repeated-measures ANOVA revealed an effect of Group $\left(F_{(3,29)}=37.47, p<0.001\right)$ in the extinction LTM tests. The Bonferroni post hoc test showed that RU486 disrupted the formation of extinction LTM (both $p<$ 0.05 ; Fig. $7 e$ ). RU486 also prevented the decrease in fear reinstatement induced by novelty $(p<0.05$; Fig. $7 f)$. These results indicate that hippocampal GRs act as a behavioral tag of extinction memory.

\section{Hippocampal Erk1/2 but NotPKA acts as a behavioral tag of extinction}

Hippocampal PKA but not Erk1/2 has been shown to be a behavioral tag of fear memory (Moncada et al., 2011). PKA and Erk1/2 are the main downstream protein kinases of $\beta A R$ and GR, respectively. We investigated whether these two kinases serve as behavioral tags of extinction. Rats were exposed to the OF $1 \mathrm{~h}$ before or after extinction. Rp-cAMPS or U0126 was micro-infused into the CA1 immediately before extinction. To examine the effect of Rp-cAMPS on the enhancement of extinction induced by the OF, 
five groups of rats were included (Ext, Nov-Saline-Ext, Nov-Rp-cAMPS-Ext, Saline-Ext-Nov, and Rp-cAMPS-ExtNov; $n=9$ per group; Fig. $8 a$ ). A repeated-measures ANOVA was conducted to analyze the extinction LTM data, revealing an effect of Group $\left(F_{(4,40)}\right.$ $=9.64, p<0.001)$. The Bonferroni post hoc test showed that Rp-cAMPS did not affect the novelty-induced enhancement of extinction LTM (all ps > 0.05; Fig. $8 b$ ). Novelty decreased fear reinstatement $\left(F_{(4,44)}=7.59, p<0.001\right)$, which was not affected by Rp-cAMPS (both $p$ s $>0.05$; Fig. 8 c). To examine the effect of U0126 on the enhancement of extinction induced by OF exploration, five groups of rats were included (Ext, Nov-Saline-Ext, Nov-U0126-Ext, Saline-Ext-Nov, and U0126-Ext-Nov; $n=9-10$ per group; Fig. $8 d)$. A repeated-measures ANOVA was conducted to analyze the extinction LTM data, revealing an effect of Group $\left(F_{(4,44)}\right.$ $=33.61, p<0.001)$. The Bonferroni post hoc test showed that U0126 disrupted extinction LTM 2 and $7 \mathrm{~d}$ after extinction compared with the group without OF exploration (all $p s<0.05$; Fig. $8 e$ ). Novelty decreased fear reinstatement $\left(F_{(4,48)}=\right.$ $12.96, p<0.001)$, which was prevented by U0126 (both $p s<0.05$; Fig. $8 f$ ). These results indicate that hippocampal Erk1/2 is involved in the behavioral tagging of extinction.

To confirm the role of Erk1/2 in the behavioral tagging of extinction, we investigated the effect of U0126 on the activity of hippocampal Erk1/2 after noveltypromoted extinction. U0126 was microinfused into the CA1 immediately before extinction, which was conducted $1 \mathrm{~h}$ be-

fore or after OF exploration. The rats were decapitated $1 \mathrm{~h}$ after extinction or OF exploration. Five groups of rats were included (Vehicle-Ext, Nov-Vehicle-Ext, Nov-U0126-Ext, Vehicle-Ext-Nov, and U0126-Ext-Nov; $n=6$ per group; Fig. $8 g$ ). The level of pErk1/2 was elevated by extinction and further augmented by exposure to novelty before $\left(F_{(3,23)}=17.45, p<0.001\right.$; Nov-Vehicle-Ext vs Vehicle-Ext: $t=3.17, p<0.05)$ and after $\left(F_{(3,23)}=21.13, p<0.001\right.$; Vehicle-Ext-Nov vs Vehicle-Ext: $t=$ 3.05, $p<0.05$ ) extinction, which was blocked by U0126 (both ps $<0.001$; Fig. $8 h, i)$. These results indicate that hippocampal Erk1/2 but not PKA acts as a behavioral tag of extinction memory.

\section{Discussion}

In the present study, we investigated the effect of novelty on fear extinction and the underlying mechanism. Exposure to a novel but not familiar OF $1 \mathrm{~h}$ before or after extinction enhanced extinction LTM and reduced reinstatement. Antagonists of $\beta$ ARs and GRs blocked the extinction-enhancing effect of novelty. Hippocampal Erk1/2 but not PKA served as a behavioral tag of extinction (Fig. 9). contextual fear conditioning. b

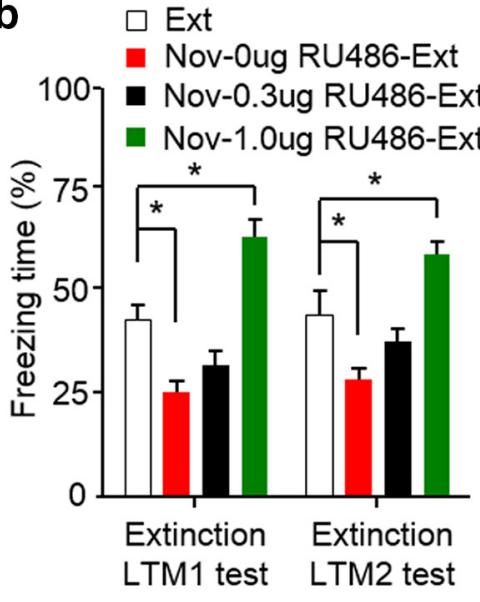

e

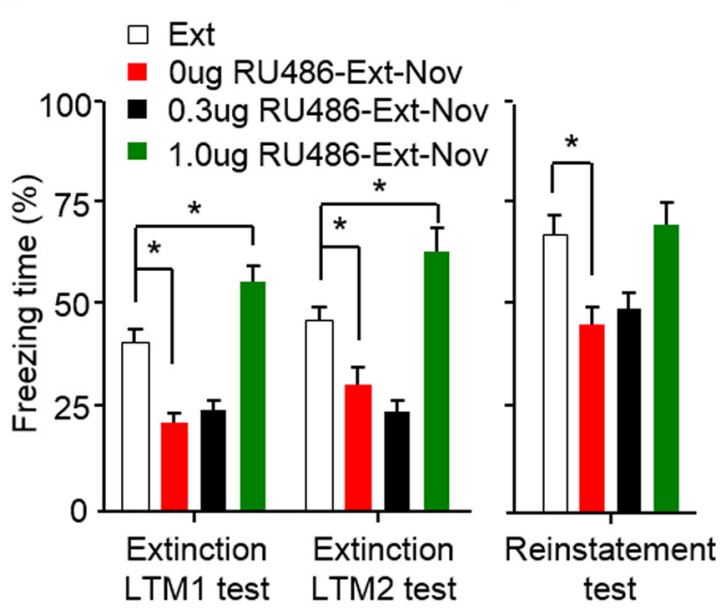

C

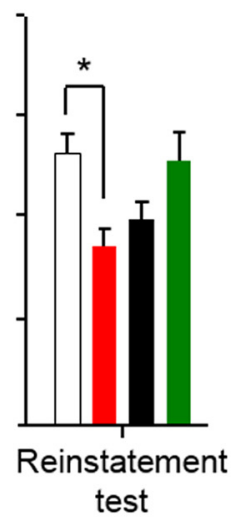

f

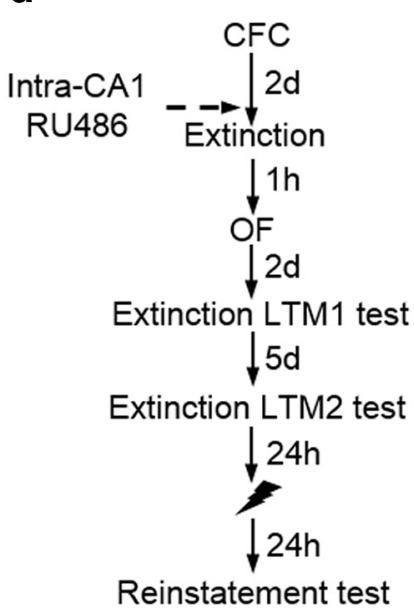

Figure 7. Hippocampal GRs act as a behavioral tag of extinction. $\boldsymbol{a}, \boldsymbol{d}$, The GR inhibitor RU486 was micro-infused into the CA1 before extinction (Ext). The OF was presented $1 \mathrm{~h}$ before or after extinction. Extinction LTM and reinstatement were then tested ( $n=8-10$ per group). $\boldsymbol{b}, \boldsymbol{c}$, RU486 prevented the formation of extinction LTM and inhibited the reduction of reinstatement decrease in reinstatement induced by novelty presented after extinction. Data are expressed as mean $\pm \mathrm{SEM} ;{ }^{*} p<0.05$. CFC,

\section{Extinction-enhancing Effect of Novelty}

The pharmacological or behavioral modulation of extinction may have consequences in two aspects: extinction or the original fear memory traces (Richardson et al., 2004; Quirk et al., 2010). The novelty-induced enhancement of extinction did not erase the original fear memory because we found that extinguished fear could be reinstated in rats that were exposed to novelty. The new CS-no US extinction memory also involves acquisition, consolidation, and storage processes (Orsini and Maren, 2012; Maren et al., 2013). After acquisition, the memory traces undergo a consolidation process to be persistently stored, which is proposed to be completed within several hours $(\sim 6 \mathrm{~h})$ after acquisition (Bourtchouladze et al., 1998; Schafe et al., 1999). Exploring novelty $1 \mathrm{~h}$ but not $6 \mathrm{~h}$ after extinction enhanced extinction memory, indicating that novelty promoted the consolidation of extinction memory rather than influenced the storage of extinction memory traces. Although exposure to novelty pre-extinction did not facilitate the rate of extinction, we cannot exclude the possibility that enhanced extinction memory induced by novelty pre-extinction is attributable to the promotion of extinction acquisition. Therefore, we propose that novelty improves extinction memory by promoting the consolidation of extinction memory. 


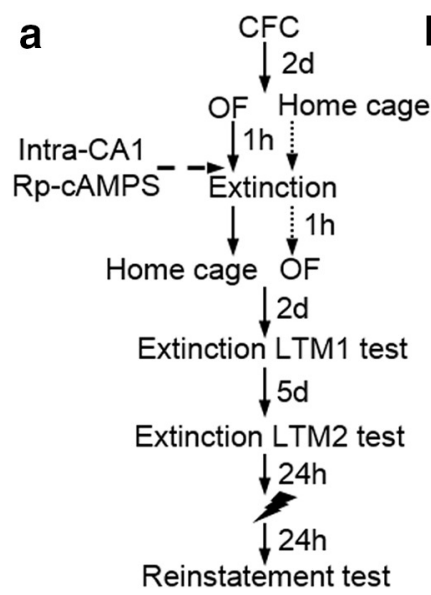

b

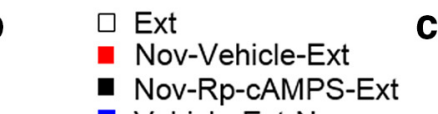

d
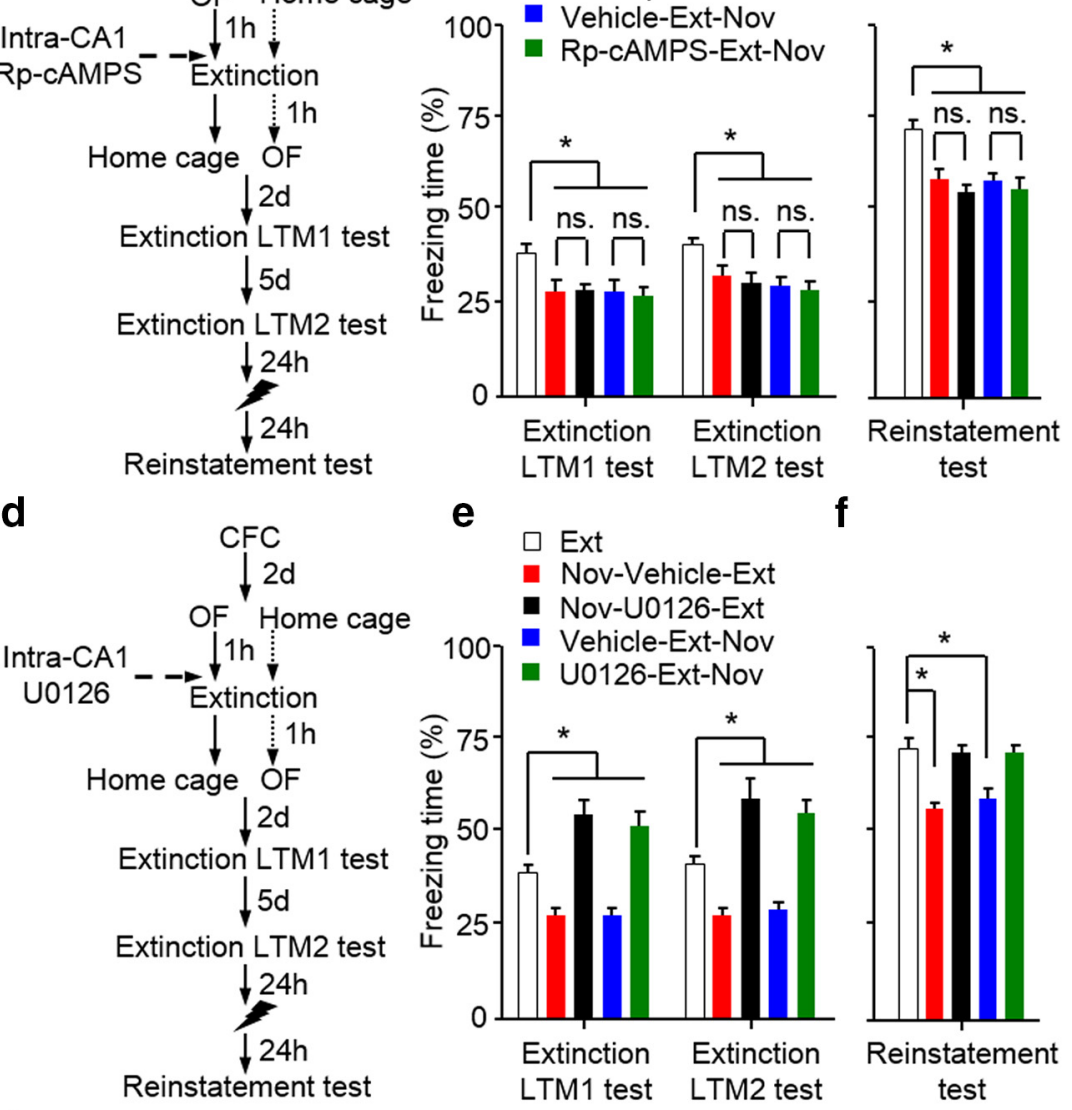

g

h
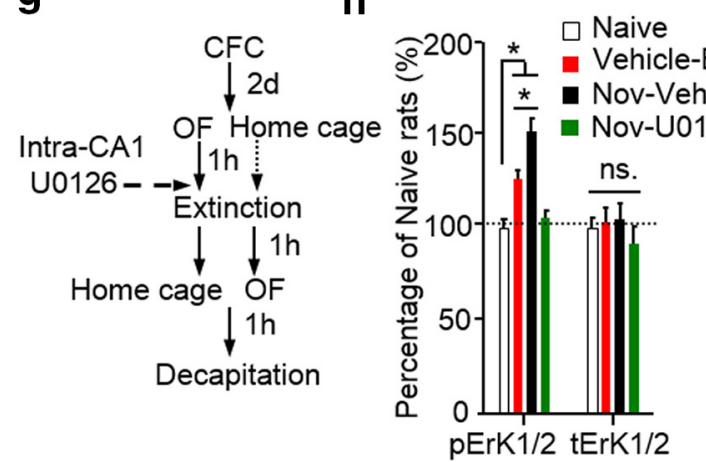

i

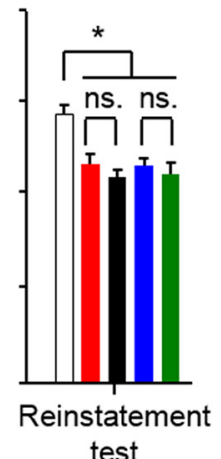

C

A large body of evidence showed that novelty exploration before or after acquisition facilitates the transformation from short-term memory (STM) to LTM with regard to several hippocampus-dependent memories, including inhibitory avoidance memory, spatial object recognition, and contextual fear memory (Moncada and Viola, 2007; Ballarini et al., 2009; de Carvalho Myskiw et al., 2013). Moreover, exposure to novelty before a memory test enhanced both recent and remote memories (Izquierdo and McGaugh, 1985; Izquierdo et al., 2000, 2001, 2003). In addition to the reinforcement of LTM formation and retrieval, novelty also prevents the footshock-induced impairment of spatial memory, suggesting a reinforcing effect of novelty on the stabilization of memory traces (Almaguer-Melian et al., 2012). Novelty promotes the formation of extinction LTM (de Carvalho Myskiw et al., 2013), and we further demonstrated that novelty reinforced long-lasting extinction memory. Previous research also showed that hippocampal LTP in freely moving rats was reversed by spatial novelty, suggesting an inhibitory interaction between novelty and the formation of long-lasting synaptic plasticity (Xu et al., 1998). A "noveltyinduced" retrograde amnesia phenomenon was also reported, in which exploration of a novel environment shortly after acquisition of inhibitory avoidance fear impaired memory retention (Izquierdo et al., 1999). These effects of novelty on LTP or memory cannot be explained by the STC or behavioral tagging hypothesis. We propose that different mechanisms may underlie the effect of novelty on memory, depending on the type, strength, and state of memory.

In addition to protein synthesis in the brain, novelty also increases sympathetic nervous system activity, including elevated levels of adrenal hormones, corticosterone, and epinephrine. The emotional tagging hypothesis proposes that the emotional content of an experience promotes the formation of LTM that is related to that event. The present results demonstrated the involvement of hippocampal $\beta A R s$ and GRs in the extinctionenhancing effect of novelty, suggesting that this effect may be caused by the novelty-induced promotion of emotional valence, arousal, and attention (Lane et al., 1999). Other brain areas (e.g., basolateral amygdala, BLA) may also be involved in the extinction-enhancing effect of novelty. Although the formation of extinction LTM promoted by novelty does not re-
Figure 8. Hippocampal Erk1/2 but not PKA is a behavioral tag of extinction. $\boldsymbol{a}, \boldsymbol{d}$, The PKA inhibitor Rp-CAMPS or Erk1/2 inhibitor U0126 was micro-infused into the (A1 before extinction. The OF was presented $1 \mathrm{~h}$ before or after extinction (Ext). Extinction LTM and reinstatement were then tested ( $n=9-10$ per group). $\boldsymbol{b}, \boldsymbol{c}$, Rp-CAMPS did not affect the enhancement of extinction LTM or decrease in fear reinstatement induced by novelty (Nov) pre-extinction or post-extinction. $\boldsymbol{e}, \boldsymbol{f}, \mathrm{U} 0126$ prevented the formation of extinction LTM and decrease in reinstatement promoted by novelty. $\boldsymbol{g}$, Time line and representative Western blots. U0126 was micro-infused into the CA1 immediately before extinction. The $0 \mathrm{~F}$ was presented $1 \mathrm{~h}$ before or after extinction. The rats were decapitated $2 \mathrm{~h}$ after extinction ( $n=6$ per group). $\boldsymbol{h}, \boldsymbol{i}$, U0126 blocked the activation of hippocampal Erk1/2 induced by noveltypromoted extinction. Data are expressed as mean \pm SEM; ${ }^{*} p<0.05$. pErk1/2, phosphorylated Erk1/2; tErk1/2, total Erk1/2; CFC, contextual fear conditioning; PKA, protein kinase A. 


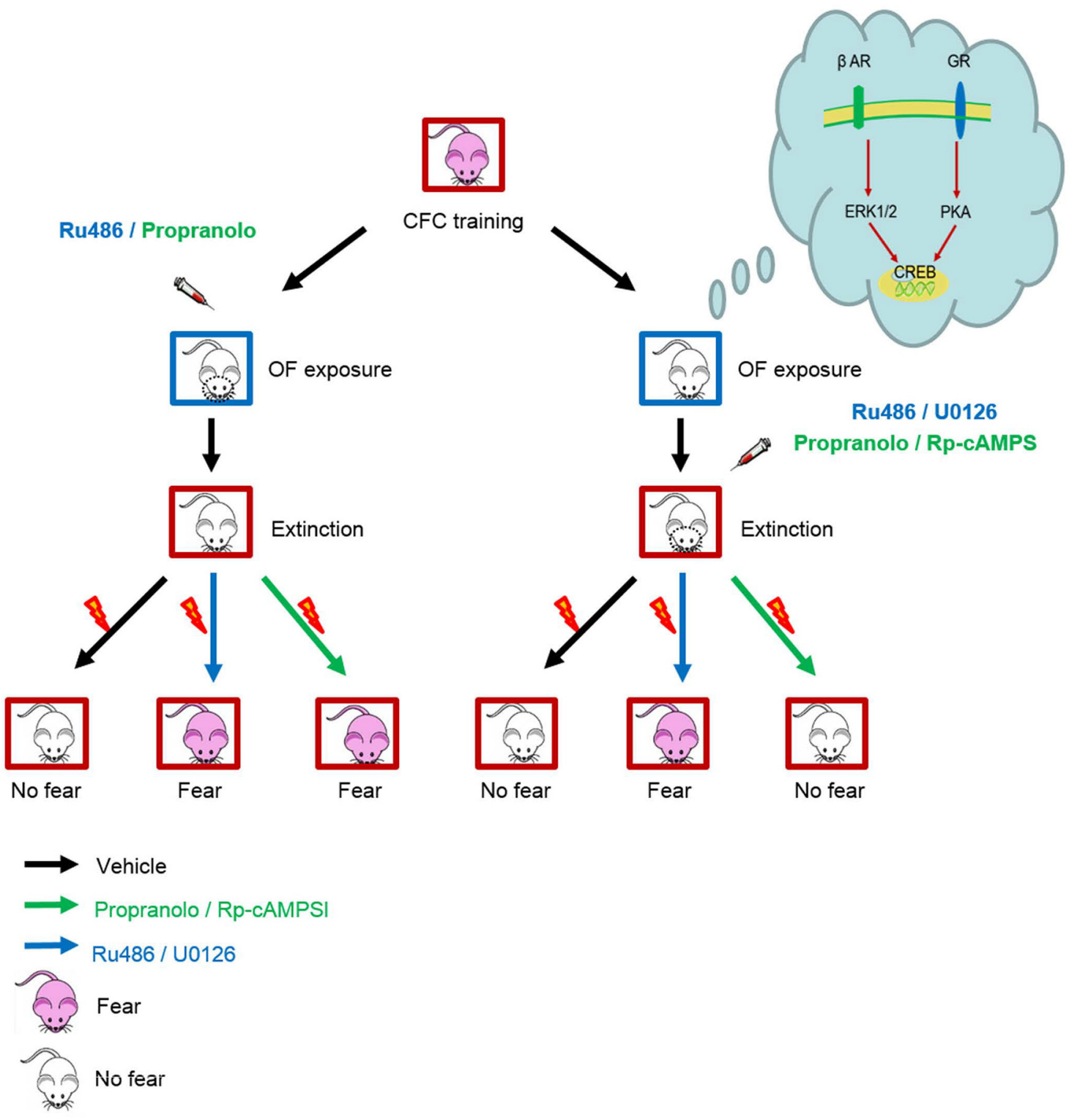

Figure 9. Model of the roles of hippocampal $\beta A R$ s and GRs in the synthesis of PRPs and setting of fear extinction tagging. Novelty exploration activated the GR-Erk1/2-CREB and $\beta$ AR-PKA-CREB pathways in the hippocampus, promoted extinction LTM, and prevented reinstatement. When the GR antagonist RU486 and $\beta$ AR inhibitor propranolol were infused before novelty exposure, the effect of novelty exposure on fear extinction was prevented. However, when injected before extinction, RU486 and the Erk1/2 inhibitor U0126 but not propranolol or the PKA inhibitor Rp-cAMPS impaired the effect of novelty exposure on fear extinction. Thus, hippocampal GRs and Erk $1 / 2$ but not $\beta$ ARs or PKA may serve as behavioral tags to promote extinction LTM. CFC, contextual fear conditioning.

quire protein synthesis in the BLA (de Carvalho Myskiw et al., 2013), the transient activation of the noradrenergic system in the BLA may also regulate the extinction process in the CA1. The memory-enhancing effect of the hippocampal glucocorticoid system has been previously shown to require noradrenergic activity in the BLA (Quirarte et al., 1997). Although stress extensively affects adrenal hormones (de Kloet et al., 2005), the effect of stress on extinction memory is different when subjects are exposed to novelty, which may be attributable to the emotional states induced by these two experiences, for example, cold swim stress but not novelty was shown to induce anxiety-like behavior (Avital et al., 2001). However, it is still possible that a mind-stressful effect when exploring novelty may contribute to the improvement of extinction induced by novelty.

\section{Plasticity-related protein synthesis and synaptic tags in novelty-enhanced extinction}

Based on the STC hypothesis, a behavioral tagging hypothesis was proposed to explain the memory-enhancing effect of novelty (Viosca et al., 2007). Synaptic tags in the activated synapses that are triggered by weak training capture the PRPs that are induced by novelty exploration to drive the formation of LTM (Moncada and Viola, 2007; Moncada et al., 2011). To facilitate the transformation from the STM to LTM of fear memory, novelty engages several signaling pathways in the hippocampus. Hippocampal dopamine D1/D5 receptors and $\beta$ ARs are selectively responsive to PRP synthesis but do not serve as behavioral tags of fear memory (Moncada et al., 2011). NMDA receptors, CaMKII, L-type voltage-dependent calcium channels, and PKA are involved in the synaptic tagging process associated with LTP and have 
been shown to be potential behavioral tags ( $L u$ et al., 2011; Moncada et al., 2011; de Carvalho Myskiw et al., 2014). In particular, BDNF is sufficient to induce the transformation of early-LTP into late-LTP, suggesting that BDNF signaling is involved in synaptic tagging (Rex et al., 2007). Moreover, the inhibition of Erk1/2, which is involved in the synaptic tagging process associated with LTD, did not block the noveltyinduced formation of LTM (Moncada et al., 2011). These studies suggest that a synaptic tagging process associated with LTP underlies LTM formation.

A synaptic tag is set by extinction learning, which captures the PRPs that are synthesized because of novelty exposure (de Carvalho Myskiw et al., 2013). In the present study, novelty exposure activated the hippocampal GR-Erk1/2-CREB and $\beta$ AR-PKACREB pathways. The inhibition of GRs or Erk1/2 in the hippocampus before extinction impaired the enhancing effect of novelty exposure, whereas the suppression of $\beta$ ARs or PKA did not have such an effect, suggesting that GRs and Erk1/2 but not $\beta A R s$ or PKA are captured by the synaptic tag. Therefore, hippocampal GRs and Erk1/2 but not $\beta$ ARs or PKA may serve as behavioral tags to promote extinction LTM. Furthermore, we found that the enhancement of fear extinction involved BDNF and CREB in the hippocampus, and PKA and Erk1/2 may act as mediators of $\beta A R$ s and GRs to activate CREB and BDNF, which is crucial for the synthesis of PRPs and synaptic tagging (Casadio et al., 1999; Barco et al., 2002). Moreover, novelty enhances the phosphorylation of CREB in the hippocampus (Viola et al., 2000) and activates hippocampal Erk1/2 (Izquierdo et al., 2001). Considering that Erk1/2 is a synaptic tag of LTD and PKA is a synaptic tag of LTP (Moncada et al., 2011), we conclude that novelty may increase the synaptic tags of the consolidation of extinction memory and promote extinction LTM. Nevertheless, other LTP synaptic tagging-related molecules (e.g., BDNF) may also be important for fear extinction. BDNF promotes LTP-related protein changes in hippocampus (Rex et al., 2007), which is probably mediated by Erk1/2 (Hetman et al., 1999), resulting in the upregulation of PRPs. Both LTP and LTD are important for extinction (Fiorenza et al., 2012; Milad and Quirk, 2012; Orsini and Maren, 2012), and a “cross-tagging” phenomenon has also been reported (Sajikumar and Frey, 2004).

The novel feature of an unfamiliar environment is a main factor that contributes to the extinction-enhancing effect. Repeated exposure to a novel environment allows it to become a familiar one, which is termed habituation (Feigley et al., 1972; Leussis and Bolivar, 2006). The formation of habituation is indeed a learning process that requires the immediate posttraining involvement of NMDA receptors (Izquierdo et al., 1992) and CaMKII (Wolfman et al., 1999). An interesting issue is whether habituation learning is also facilitated by extinction, but this requires further investigation. Another important issue is whether the first extinction trial can serve as memory retrieval (Izquierdo and McGaugh, 1985; Izquierdo et al., 2000, 2001, 2003). If so, then novelty would enhance the reactivation of memory traces upon the initiation of extinction. Our results showed that the first trial of extinction and the extinction rate were unaltered by pre-extinction novelty. Therefore, specific mechanisms may underlie the differences between the effect of novelty on memory retrieval and the initiation of extinction.

\section{Concluding remarks}

In summary, we found that both hippocampal $\beta A R$ and GR are involved in the extinction-enhancing effect of novelty because of their roles in the synthesis of the PRPs. The hippocampal PKACREB and Erk1/2-CREB signaling pathways, respectively, appeared to mediate the effects of $\beta A R$ and GR. Hippocampal GR and Erk1/2 but not $\beta$ AR or PKA may serve as behavioral tags to promote extinction LTM. Uncovering the mechanism of the behavioral tagging of extinction may improve the efficacy of exposure therapy for post-traumatic stress disorder or anxiety-related disorders.

\section{References}

Almaguer-Melian W, Bergado-Rosado J, Pavon-Fuentes N, Alberti-Amador E, Mercerón-Martínez D, Frey JU (2012) Novelty exposure overcomes foot shock-induced spatial-memory impairment by processes of synaptic-tagging in rats. Proc Natl Acad Sci U S A 109:953-958. CrossRef Medline

Avital A, Richter-Levin G, Leschiner S, Spanier I, Veenman L, Weizman A, Gavish M (2001) Acute and repeated swim stress effects on peripheral benzodiazepine receptors in the rat hippocampus, adrenal, and kidney. Neuropsychopharmacology 25:669-678. CrossRef Medline

Ballarini F, Moncada D, Martinez MC, Alen N, Viola H (2009) Behavioral tagging is a general mechanism of long-term memory formation. Proc Natl Acad Sci U S A 106:14599-14604. CrossRef Medline

Barco A, Alarcon JM, Kandel ER (2002) Expression of constitutively active CREB protein facilitates the late phase of long-term potentiation by enhancing synaptic capture. Cell 108:689-703. CrossRef Medline

Berman DE, Dudai Y (2001) Memory extinction, learning anew, and learning the new: dissociations in the molecular machinery of learning in cortex. Science 291:2417-2419. CrossRef Medline

Bourtchouladze R, Abel T, Berman N, Gordon R, Lapidus K, Kandel ER (1998) Different training procedures recruit either one or two critical periods for contextual memory consolidation, each of which requires protein synthesis and PKA. Learn Mem 5:365-374. Medline

Campolongo P, Morena M, Scaccianoce S, Trezza V, Chiarotti F, Schelling G, Cuomo V, Roozendaal B (2013) Novelty-induced emotional arousal modulates cannabinoid effects on recognition memory and adrenocortical activity. Neuropsychopharmacology 38:1276-1286. CrossRef Medline

Casadio A, Martin KC, Giustetto M, Zhu H, Chen M, Bartsch D, Bailey CH, Kandel ER (1999) A transient, neuron-wide form of CREB-mediated long-term facilitation can be stabilized at specific synapses by local protein synthesis. Cell 99:221-237. CrossRef Medline

Chai N, Liu JF, Xue YX, Yang C, Yan W, Wang HM, Luo YX, Shi HS, Wang JS, Bao YP, Meng SQ, Ding ZB, Wang XY, Lu L (2014) Delayed noradrenergic activation in the dorsal hippocampus promotes the long-term persistence of extinguished fear. Neuropsychopharmacology 39:1933-1945. CrossRef Medline

Chandramohan Y, Droste SK, Reul JM (2007) Novelty stress induces phospho-acetylation of histone $\mathrm{H} 3$ in rat dentate gyrus granule neurons through coincident signalling via the $\mathrm{N}$-methyl-D-aspartate receptor and the glucocorticoid receptor: relevance for $\mathrm{c}$-fos induction. J Neurochem 101:815-828. CrossRef Medline

Chhatwal JP, Stanek-Rattiner L, Davis M, Ressler KJ (2006) Amygdala BDNF signaling is required for consolidation but not encoding of extinction. Nat Neurosci 9:870-872. CrossRef Medline

Davis CD, Jones FL, Derrick BE (2004) Novel environments enhance the induction and maintenance of long-term potentiation in the dentate gyrus. J Neurosci 24:6497-6506. CrossRef Medline

de Carvalho Myskiw J, Benetti F, Izquierdo I (2013) Behavioral tagging of extinction learning. Proc Natl Acad Sci U S A 110:1071-1076. CrossRef Medline

de Carvalho Myskiw J, Furini CR, Benetti F, Izquierdo I (2014) Hippocampal molecular mechanisms involved in the enhancement of fear extinction caused by exposure to novelty. Proc Natl Acad Sci U S A 111:4572-4577. CrossRef Medline

de Kloet ER, Joëls M, Holsboer F (2005) Stress and the brain: from adaptation to disease. Nat Rev Neurosci 6:463-475. CrossRef Medline

Feigley DA, Parsons PJ, Hamilton LW, Spear NE (1972) Development of 
habituation to novel environments in the rat. J Comp Physiol Psychol 79:443-452. CrossRef Medline

Fiorenza NG, Rosa J, Izquierdo I, Myskiw JC (2012) Modulation of the extinction of two different fear-motivated tasks in three distinct brain areas. Behav Brain Res 232:210-216. CrossRef Medline

Frey U, Morris RG (1997) Synaptic tagging and long-term potentiation. Nature 385:533-536. CrossRef Medline

Frey U, Morris RG (1998) Synaptic tagging: implications for late maintenance of hippocampal long-term potentiation. Trends Neurosci 21:181188. CrossRef Medline

Haaker J, Gaburro S, Sah A, Gartmann N, Lonsdorf TB, Meier K, Singewald N, Pape HC, Morellini F, Kalisch R (2013) Single dose of L-dopa makes extinction memories context-independent and prevents the return of fear. Proc Natl Acad Sci U S A 110:E2428-E2436. CrossRef Medline

Heldt SA, Stanek L, Chhatwal JP, Ressler KJ (2007) Hippocampusspecific deletion of BDNF in adult mice impairs spatial memory and extinction of aversive memories. Mol Psychiatry 12:656-670. CrossRef Medline

Hetman M, Kanning K, Cavanaugh JE, Xia Z (1999) Neuroprotection by brain-derived neurotrophic factor is mediated by extracellular signalregulated kinase and phosphatidylinositol 3-kinase. J Biol Chem 274: 22569-22580. CrossRef Medline

Izquierdo I, McGaugh JL (1985) Effect of a novel experience prior to training or testing on retention of an inhibitory avoidance response in mice: involvement of an opioid system. Behav Neural Biol 44:228-238. CrossRef Medline

Izquierdo I, da Cunha C, Rosat R, Jerusalinsky D, Ferreira MB, Medina JH (1992) Neurotransmitter receptors involved in post-training memory processing by the amygdala, medial septum, and hippocampus of the rat. Behav Neural Biol 58:16-26. CrossRef Medline

Izquierdo I, Schröder N, Netto CA, Medina JH (1999) Novelty causes timedependent retrograde amnesia for one-trial avoidance in rats through NMDA receptor- and CaMKII-dependent mechanisms in the hippocampus. Eur J Neurosci 11:3323-3328. CrossRef Medline

Izquierdo LA, Barros DM, Medina JH, Izquierdo I (2000) Novelty enhances retrieval of one-trial avoidance learning in rats 1 or 31 dafter training unless the hippocampus is inactivated by different receptor antagonists and enzyme inhibitors. Behav Brain Res 117:215-220. CrossRef Medline

Izquierdo LA, Viola H, Barros DM, Alonso M, Vianna MR, Furman M, Levi de Stein M, Szapiro G, Rodrigues C, Choi H, Medina JH, Izquierdo I (2001) Novelty enhances retrieval: molecular mechanisms involved in rat hippocampus. Eur J Neurosci 13:1464-1467. CrossRef Medline

Izquierdo LA, Barros DM, Medina JH, Izquierdo I (2003) Exposure to novelty enhances retrieval of very remote memory in rats. Neurobiol Learn Mem 79:51-56. CrossRef Medline

Kurumaji A, Umino M, Nishikawa T (2011) Effects of novelty stress on hippocampal gene expression, corticosterone and motor activity in mice. Neurosci Res 71:161-167. CrossRef Medline

Lane RD, Chua PM, Dolan RJ (1999) Common effects of emotional valence, arousal and attention on neural activation during visual processing of pictures. Neuropsychologia 37:989-997. CrossRef Medline

Leussis MP, Bolivar VJ (2006) Habituation in rodents: a review of behavior, neurobiology, and genetics. Neurosci Biobehav Rev 30:1045-1064. CrossRef Medline

Li FQ, Xue YX, Wang JS, Fang Q, Li YQ, Zhu WL, He YY, Liu JF, Xue LF, Shaham Y, Lu L (2010) Basolateral amygdala cdk5 activity mediates consolidation and reconsolidation of memories for cocaine cues. J Neurosci 30:10351-10359. CrossRef Medline

Li S, Cullen WK, Anwyl R, Rowan MJ (2003) Dopamine-dependent facilitation of LTP induction in hippocampal CA1 by exposure to spatial novelty. Nat Neurosci 6:526-531. Medline

Lu L, Hope BT, Dempsey J, Liu SY, Bossert JM, Shaham Y (2005) Central amygdala ERK signaling pathway is critical to incubation of cocaine craving. Nat Neurosci 8:212-219. CrossRef Medline

Lu Y, Ji Y, Ganesan S, Schloesser R, Martinowich K, Sun M, Mei F, Chao MV, Lu B (2011) TrkB as a potential synaptic and behavioral tag. J Neurosci 31:11762-11771. CrossRef Medline

Maren S, Phan KL, Liberzon I (2013) The contextual brain: implications for fear conditioning, extinction and psychopathology. Nat Rev Neurosci 14:417-428. CrossRef Medline
McGaugh JL (2000) Memory—a century of consolidation. Science 287: 248-251. CrossRef Medline

McIntyre CK, McGaugh JL, Williams CL (2012) Interacting brain systems modulate memory consolidation. Neurosci Biobehav Rev 36:1750-1762. CrossRef Medline

Milad MR, Quirk GJ (2012) Fear extinction as a model for translational neuroscience: ten years of progress. Annu Rev Psychol 63:129-151. CrossRef Medline

Moncada D, Viola H (2006) Phosphorylation state of CREB in the rat hippocampus: a molecular switch between spatial novelty and spatial familiarity? Neurobiol Learn Mem 86:9-18. CrossRef Medline

Moncada D, Viola H (2007) Induction of long-term memory by exposure to novelty requires protein synthesis: evidence for a behavioral tagging. J Neurosci 27:7476-7481. CrossRef Medline

Moncada D, Ballarini F, Martinez MC, Frey JU, Viola H (2011) Identification of transmitter systems and learning tag molecules involved in behavioral tagging during memory formation. Proc Natl Acad Sci U S A 108: 12931-12936. CrossRef Medline

Monti B, Berteotti C, Contestabile A (2006) Subchronic rolipram delivery activates hippocampal CREB and arc, enhances retention and slows down extinction of conditioned fear. Neuropsychopharmacology 31:278-286. CrossRef Medline

Morgan MA, LeDoux JE (1999) Contribution of ventrolateral prefrontal cortex to the acquisition and extinction of conditioned fear in rats. Neurobiol Learn Mem 72:244-251. CrossRef Medline

Mueller GE, Pilzecker A (1900) Experimentelle beitrage zur lehre vom gedachtniss. Zeitsch Psychol 1:1-288.

Nyakas C, De Kloet ER, Veldhuis HD, Bohus B (1983) Hippocampal corticosterone receptors and novelty-induced behavioral activity: effect of kainic acid lesion in the hippocampus. Brain Res 288:219-228. CrossRef Medline

Orsini CA, Maren S (2012) Neural and cellular mechanisms of fear and extinction memory formation. Neurosci Biobehav Rev 36:1773-1802. CrossRef Medline

Pavlov IP (1927) Conditioned reflexes. London: Oxford UP.

Paxinos G, Watson C (2005) The rat brain in stereotaxic coordinates, 5 Edition. Amsterdam: Elsevier Academic.

Pisa M, Martin-Iverson MT, Fibiger HC (1988) On the role of the dorsal noradrenergic bundle in learning and habituation to novelty. Pharmacol Biochem Behav 30:835-845. CrossRef Medline

Quirarte GL, Roozendaal B, McGaugh JL (1997) Glucocorticoid enhancement of memory storage involves noradrenergic activation in the basolateral amygdala. Proc Natl Acad Sci U S A 94:14048-14053. CrossRef Medline

Quirk GJ, ParéD, Richardson R, Herry C, Monfils MH, Schiller D, Vicentic A (2010) Erasing fear memories with extinction training. J Neurosci 30: 14993-14997. CrossRef Medline

Ren ZY, Liu MM, Xue YX, Ding ZB, Xue LF, Zhai SD, Lu L (2013) A critical role for protein degradation in the nucleus accumbens core in cocaine reward memory. Neuropsychopharmacology 38:778-790. CrossRef Medline

Rescorla RA, Heth CD (1975) Reinstatement of fear to an extinguished conditioned stimulus. J Exp Psychol Anim Behav Process 1:88-96. CrossRef Medline

Rex CS, Lin CY, Kramár EA, Chen LY, Gall CM, Lynch G (2007) Brainderived neurotrophic factor promotes long-term potentiation-related cytoskeletal changes in adult hippocampus. J Neurosci 27:3017-3029. CrossRef Medline

Richardson R, Ledgerwood L, Cranney J (2004) Facilitation of fear extinction by D-cycloserine: theoretical and clinical implications. Learn Mem 11:510-516. CrossRef Medline

Sajikumar S, Frey JU (2004) Late-associativity, synaptic tagging, and the role of dopamine during LTP and LTD. Neurobiol Learn Mem 82:12-25. CrossRef Medline

Schafe GE, Nadel NV, Sullivan GM, Harris A, LeDoux JE (1999) Memory consolidation for contextual and auditory fear conditioning is dependent on protein synthesis, PKA, and MAP kinase. Learn Mem 6:97-110. Medline

Shires KL, Da Silva BM, Hawthorne JP, Morris RG, Martin SJ (2012) Synaptic tagging and capture in the living rat. Nat Commun 3:1246. CrossRef Medline

Straube T, Korz V, Frey JU (2003a) Bidirectional modulation of long-term 
potentiation by novelty-exploration in rat dentate gyrus. Neurosci Lett 344:5-8. CrossRef Medline

Straube T, Korz V, Balschun D, Frey JU (2003b) Requirement of betaadrenergic receptor activation and protein synthesis for LTPreinforcement by novelty in rat dentate gyrus. J Physiol 552:953-960. CrossRef Medline

Sun LL, Zhang Y, Liu JF, Wang J, Zhu WL, Zhao LY, Xue YX, Lu L, Shi J (2013) Role of melanin-concentrating hormone in the nucleus accumbens shell in rats behaviourally sensitized to methamphetamine. Int J Neuropsychopharmacol 16:1767-1780. CrossRef Medline

Suo L, Zhao L, Si J, Liu J, Zhu W, Chai B, Zhang Y, Feng J, Ding Z, Luo Y, Shi H, Shi J, Lu L (2013) Predictable chronic mild stress in adolescence increases resilience in adulthood. Neuropsychopharmacology 38:13871400. CrossRef Medline

Viola H, Furman M, Izquierdo LA, Alonso M, Barros DM, de Souza MM, Izquierdo I, Medina JH (2000) Phosphorylated cAMP response elementbinding protein as a molecular marker of memory processing in rat hippocampus: effect of novelty. J Neurosci 20:RC112. Medline
Viosca J, Jancic D, López-Atalaya JP, Benito E (2007) Hunting for synaptic tagging and capture in memory formation. J Neurosci 27:12761-12763. CrossRef Medline

Wolfman C, Izquierdo LA, Schröder N, Izquierdo I (1999) Intra-hippocampal KN-62 hinders the memory of habituation acquired alone, but not simultaneously with a water-finding task. Behav Pharmacol 10:99-104. CrossRef Medline

Xu L, Anwyl R, Rowan MJ (1998) Spatial exploration induces a persistent reversal of long-term potentiation in rat hippocampus. Nature 394:891894. CrossRef Medline

Xue YX, Luo YX, Wu P, Shi HS, Xue LF, Chen C, Zhu WL, Ding ZB, Bao YP, Shi J, Epstein DH, Shaham Y, Lu L (2012) A memory retrievalextinction procedure to prevent drug craving and relapse. Science 336: 241-245. CrossRef Medline

Yang C, Liu JF, Chai BS, Fang Q, Chai N, Zhao LY, Xue YX, Luo YX, Jian M, Han Y, Shi HS, Lu L, Wu P, Wang JS (2013) Stress within a restricted time window selectively affects the persistence of long-term memory. PLoS One 8:e59075. CrossRef Medline 